\title{
REVIEW
}

\section{Years of Contrast-Enhanced MRI: Developments, Current Challenges and Future Perspectives}

\author{
Jessica Lohrke - Thomas Frenzel · Jan Endrikat · Filipe Caseiro Alves • \\ Thomas M. Grist · Meng Law · Jeong Min Lee · Tim Leiner • \\ Kun-Cheng Li · Konstantin Nikolaou • Martin R. Prince • \\ Hans H. Schild · Jeffrey C. Weinreb · Kohki Yoshikawa · Hubertus Pietsch
}

To view enhanced content go to www.advancesintherapy.com

Received: July 23, 2015 / Published online: January 25, 2016

(C) The Author(s) 2016. This article is published with open access at Springerlink.com

\begin{abstract}
In 1988, the first contrast agent specifically designed for magnetic resonance imaging (MRI), gadopentetate dimeglumine $\left(\right.$ Magnevist $\left.{ }^{\circledR}\right)$, became available for clinical use. Since then, a plethora of studies have investigated the potential of MRI contrast agents for diagnostic imaging across the body, including the central nervous system, heart and circulation, breast, lungs, the gastrointestinal, genitourinary, musculoskeletal and lymphatic
\end{abstract}

Electronic supplementary material The online version of this article (doi:10.1007/s12325-015-0275-4) contains supplementary material, which is available to authorized users.

J. Lohrke · T. Frenzel · H. Pietsch $(\bowtie)$

MR and CT Contrast Media Research,

Bayer HealthCare, Berlin, Germany

e-mail: hubertus.pietsch@bayer.com

J. Endrikat

Global Medical Affairs Radiology, Bayer HealthCare, Berlin, Germany

J. Endrikat

Saarland University Hospital, Homburg, Germany

F. C. Alves

Medical Imaging, Coimbra Hospital and University

Centre, Coimbra, Portugal

T. M. Grist

Radiology, Medical Physics and Biomedical Engineering, University of Wisconsin, Madison, WI, USA systems, and even the skin. Today, after 25 years of contrast-enhanced (CE-) MRI in clinical practice, the utility of this diagnostic imaging modality has expanded beyond initial expectations to become an essential tool for disease diagnosis and management worldwide. CE-MRI continues to evolve, with new techniques, advanced technologies, and novel contrast agents bringing exciting opportunities for more sensitive, targeted imaging and improved patient management, along with associated clinical challenges. This review aims to provide an overview on the history of MRI

\section{Law}

Radiology and Neurological Surgery, University of South California, Keck School of Medicine, USC University Hospital, Los Angeles, CA, USA

\section{J. M. Lee}

College of Medicine, Seoul National University

Hospital, Seoul, South Korea

\section{T. Leiner}

Radiology, Utrecht University Medical Center, Utrecht, The Netherlands

K-C. Li

Radiology, Xuan Wu Hospital, Capital Medical University, Beijing, People's Republic of China

K. Nikolaou

Radiology, Ludwig-Maximilians University, University Hospitals, Munich, Germany 
and contrast media development, to highlight certain key advances in the clinical development of CE-MRI, to outline current technical trends and clinical challenges, and to suggest some important future perspectives.

Funding: Bayer HealthCare.

$\begin{array}{lcr}\begin{array}{l}\text { Keywords: Body } \\ \text { enhancement; }\end{array} & \text { imaging; } & \text { Contrast } \\ \text { Gadolinium; } & \text { MRI; }\end{array}$

Multimodality imaging; Relaxivity

\section{INTRODUCTION}

The year 2013 heralded the 25th anniversary of contrast enhancement in magnetic resonance imaging (MRI). The first gadolinium-based contrast agent (GBCA), gadopentetate dimeglumine (Magnevist ${ }^{\circledR}$ ), became available for clinical use globally in 1988 and, since then, eight further gadolinium chelates have been developed and approved in many regions worldwide.

Advances in contrast media and the technical capabilities of MRI have increased the accuracy and utility of contrast-enhanced-MRI (CE-MRI) for many different indications. Today, CE-MRI is a

M. R. Prince

Radiology, Weill Cornell Medical College,

New York, NY, USA

M. R. Prince

Columbia College of Physicians and Surgeons,

New York, NY, USA

H. H. Schild

Radiology, University of Bonn, Bonn, Germany

J. C. Weinreb

Diagnostic Radiology, Yale School of Medicine,

New Haven, CT, USA

K. Yoshikawa

Graduate Division of Medical Health Sciences,

Graduate School of Komazawa University, Tokyo, Japan valuable and established diagnostic imaging tool worldwide, used annually in approximately 30 million procedures, with more than 300 million procedures performed to date (Data on file, Bayer HealthCare). The role of CE-MRI will continue to grow in the future as new imaging techniques are integrated into clinical practice. The close relationship between clinical diagnosis and the monitoring of increasingly specific therapies is one of the most important areas for CE-MRI use, along with research into new MRI contrast agents.

The aim of this review is to outline the history of contrast media development in MRI, to describe current technologic trends and clinical challenges, and to provide an outlook on potential future developments. This article is based on previously conducted studies and does not involve any new studies of human or animal subjects performed by any of the authors.

\section{CONCEPT OF MRI AND EARLY CONTRAST MEDIA RESEARCH}

The phenomenon that came to be known as nuclear magnetic resonance (NMR) was discovered by Bloch, Bloembergen and Purcell in the 1940s [1, 2]. The first NMR images to be generated using the interaction of two magnetic gradients were not published, however, until 1973. This research was presented by Lauterbur [3] and Mansfield [4], who were awarded the Nobel Prize in Physiology or Medicine in 2003 for their work [5, 6]. In 1974, Damadian was granted a patent for his NMR imaging technique, apparatus and method for detecting cancer in tissue [7] and in 1977 he produced the first whole-body MRI machine that generated images of a live human body [8]. 
The concept that proton relaxation times could be influenced by the presence of paramagnetic ions (with the promise of increased visibility of organs or body regions) was realized shortly after this in the late 1970s [9]. Research then began into suitable paramagnetic ion complexes for use as MRI contrast agents, beginning with animal studies of manganese $\left(\mathrm{Mn}^{2+}\right)$ compounds [10-12] and ferric $\left(\mathrm{Fe}^{3+}\right)$ chloride [13].

At the 1982 annual meeting of the Radiological Society of North America (RSNA), Val Runge presented investigations of paramagnetic ions, including copper $\left(\mathrm{Cu}^{2+}\right)$, chromium $\left(\mathrm{Cr}^{3+}\right), \mathrm{Fe}^{3+}, \mathrm{Mn}^{2+}$ and gadolinium $\left(\mathrm{Gd}^{3+}\right)$ [14], outlining potential complexes that might be stable enough for clinical use as oral and intravenous contrast agents in MRI [15]. A research group at Schering AG, Germany (now Bayer HealthCare), led by Weinmann, had recognized that $\mathrm{Gd}^{3+}$ was the most effective paramagnetic ion in terms of T1 relaxivity (and thus enhancement effect), and was developing gadopentetate dimeglumine, using the commercially available diethylenetriamine penta-acetic acid chelate [16]. Clinical development collaboration between Weinmann and other centers, including Runge and Brasch, led to Runge receiving the American Society of Neuroradiology Dyke Award for demonstrating the utility of gadopentetate dimeglumine-enhanced MRI for brain imaging [17]. Weinmann subsequently published a seminal paper on the characteristics of, and initial study results for, gadopentetate dimeglumine [18], which was, as of 2008, the most cited article ever published in the American Journal of Roentgenology [19].

The first injection of gadopentetate dimeglumine in a human volunteer took place

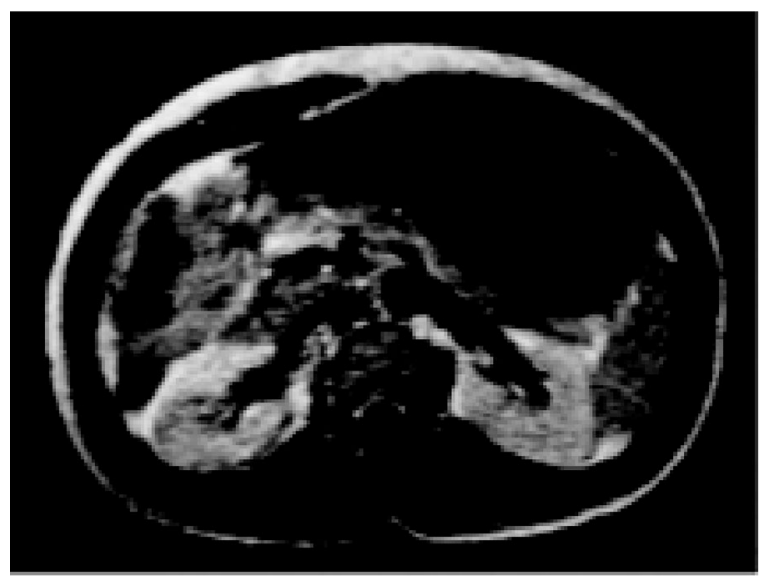

Fig. 1 Magnetic resonance image of the kidneys following the first human application of $0.05 \mathrm{mmol} / \mathrm{kg}$ gadopentetate dimeglumine (1 min p.i.) [20]. Reproduced from Laniado et al. [20] by permission of Physiol Chem Phys \& Med NMR

in Berlin on November 10, 1983, as part of a Phase I trial, showing uniform enhancement of the bladder (Fig. 1) [20]. Reports of the human pharmacokinetics of gadopentetate dimeglumine [21] and the first patient series [22] followed shortly afterward, and further clinical trials were instigated in 1985. Based on the results of these clinical trials, gadopentetate dimeglumine was approved for clinical use in the United States, Germany and Japan in 1988: the world's first contrast medium for MRI was launched.

\section{MODE OF ACTION AND PHARMACOLOGY OF GBCAS}

All GBCAs contain the paramagnetic ion of the rare earth metal gadolinium $\left(\mathrm{Gd}^{3+}\right)$, which possesses the most unpaired electrons of any stable ion (seven), creating a high magnetic moment that is effective at enhancing proton relaxation [23, 24]. Paramagnetic contrast media shorten the T1 (longitudinal) and T2 
(transversal) relaxation times of surrounding water protons to indirectly produce a signal-enhancing effect [25]. The efficiency of an agent to shorten relaxation times is called relaxivity, which is dependent on the ligand surrounding the $\mathrm{Gd}^{3+}$ ion (see later) and influenced by extrinsic factors including temperature, magnetic field strength and the tissue surroundings (water, plasma or blood). At approved clinical doses of GBCAs (typically between 0.1 and $0.3 \mathrm{mmol} / \mathrm{kg}$ body weight), the $\mathrm{T} 1$ relaxivity effect dominates and yields bright contrast $[26,27]$.

Following intravenous injection, all GBCAs distribute in the blood and extravascular-extracellular space [21, 28, 29]. GBCAs are biologically inert and rapidly eliminated by the kidneys, with the exception of gadoxetic acid $\left(\right.$ Primovist $^{\circledR} /$ Eovist $^{\circledR}$ ), gadobenate dimeglumine (Multihance ${ }^{\circledR}$ ) and gadofosveset $\left(\right.$ Vasovist $^{\circledR} /$ Ablavar $\left.^{\circledR}\right)$, which are in part taken up by hepatocytes and eliminated by the hepatobiliary system. The physicochemical properties of the different GBCAs are listed in Table 1.

As $\mathrm{Gd}^{3+}$ ions are toxic, they are chelated with organic ligands to create GBCAs with either a linear or macrocyclic structure. For GBCAs with a linear structure (e.g., gadopentetate dimeglumine, gadoxetic acid, or gadobenate dimeglumine), a polyamino-carboxylic acid backbone wraps around the $\mathrm{Gd}^{3+}$ ion, but does not fully enclose it, whereas in macrocyclic

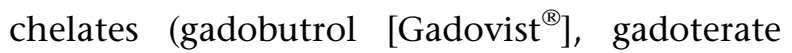
meglumine $\left[\right.$ Dotarem $\left.^{\circledR}\right]$, and gadoteridol $\left[\right.$ Prohance $\left.{ }^{\circledR}\right]$ ), a rigid "cage" with a preorganized cavity surrounds the ion. The structure of the GBCA determines its complex stability and stability in vivo. An in vitro study mimicking physiological serum conditions in renally impaired subjects demonstrated that linear agents, incubated over a 15-day period, could release substantial amounts of their $\mathrm{Gd}^{3+}$, while none of the macrocyclic agents (gadobutrol, gadoterate, gadoteridol) showed detectable $\mathrm{Gd}^{3+}$ release $(<0.1 \%$ during 15 days of incubation) [30]. This study also demonstrated that for the macrocyclic agents, charge was not an influencing parameter on complex stability. However, in vivo, the majority of a GBCA dose is excreted within a few days, even in renally impaired patients; for example, the elimination half-life of gadobutrol is $90 \mathrm{~min}$ in healthy subjects [29] and 7-26 h in those with kidney disease [31].

\section{DEVELOPMENT AND CHARACTERISTICS OF MR CONTRAST AGENTS}

Following the introduction of gadopentetate dimeglumine, the use of CE-MRI as a diagnostic imaging tool has expanded rapidly. While it was understood that $\mathrm{Gd}^{3+}$ was the most effective paramagnetic ion for proton relaxation, other paramagnetic ions have been developed for use as MRI contrast agents, including $\mathrm{Mn}^{2+}$ [32] and iron oxide compounds [33]. Today, contrast media are administered in about $25 \%$ of all MRI examinations, especially for the brain and spine, for MR angiography (MRA) and for MRI of the abdomen, breast and heart [34-36].

Five further extracellular GBCAs, exhibiting the same, passive distribution and renal excretion as gadopentetate dimeglumine, have been approved for clinical use (Table 1) [30, 37-39]: gadoterate (1989), gadoteridol (1992), gadodiamide $\left(\right.$ Omniscan ${ }^{\circledR} ;$ 1993), gadobutrol (1998) and gadoversetamide (Optimark ${ }^{\mathrm{TM}}$; 1999). With the approval of gadobenate (1998) and gadoxetic acid (2005), two agents entered the market which exhibited a different pharmacokinetic profile to the other GBCAs- 


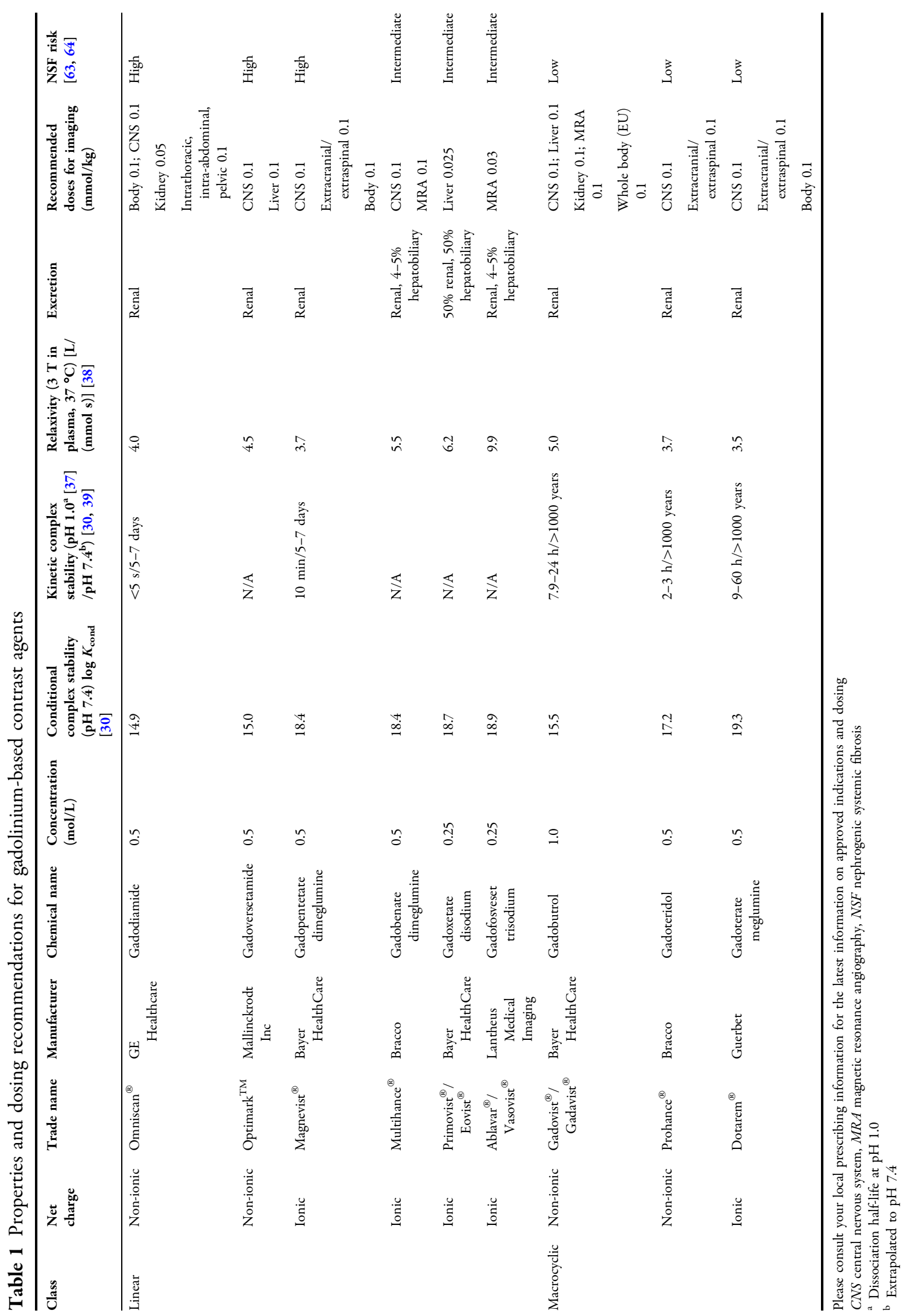


in addition to extracellular distribution, these agents are taken up to different degrees by hepatocytes (see "Abdomen" section), and thus produce a unique enhancement of liver parenchyma with partial excretion in the bile. A third group of agents are those which, after intravenous injection, remain in the circulation for prolonged periods, allowing extended imaging times for MRA. These agents include gadofosveset and the ultrasmall superparamagnetic iron oxide (USPIO) particles (which have limited commercial availability) [40].

Gadolinium-based contrast agents differ in their ability to shorten relaxation times, as a function of their relaxivity and local tissue concentration [38]. Gadobutrol was considered a 'second-generation' GBCA [41], owing to its higher concentration and relatively high relaxivity (and thus improved imaging capacity) compared with earlier agents. Gadobutrol is the only GBCA formulated at a concentration of $1.0 \mathrm{M}$, twice that of other agents. Combined with its high relaxivity in plasma, gadobutrol provides the greatest $\mathrm{T} 1$ shortening per volume of any currently available GBCA [26, 38, 42] (Table 1).

\section{SAFETY OF MR CONTRAST AGENTS}

As a class of agents, contrast media are associated with a lower prevalence of hypersensitivity reactions than other drug classes, such as pain killers or antibiotics [43]. Within contrast media, GBCAs are associated with fewer adverse drug reactions than non-ionic iodinated contrast media for X-ray and computed tomography [44]. The incidence of acute adverse reactions appears to be very low for all GBCAs [44-46]. The favorable safety profiles of gadobutrol and gadopentetate dimeglumine have been extensively documented based on millions of applications [41, 44, 47-51].

In early 2006, Grobner was the first to suggest a link between administration of a GBCA and development of nephrogenic systemic fibrosis (NSF), a rare but potentially fatal disorder in patients with end-stage renal disease [52]. Bayer HealthCare immediately initiated a major research program into this issue, including basic in vitro research and toxicologic and pharmacologic animal studies [30, 53-62], generating much of the evidence published on this topic. International expert bodies, including the Food and Drug Administration, the European Medicines Agency and the European Society of Urological Radiology, subsequently issued recommendations concerning the stability of GBCAs [63-65], classifying macrocyclic agents as having a lower risk for the development of NSF (Table 1). The reported incidence of NSF is decreasing, possibly attributable to a greater awareness of at-risk patients, lower dosing of contrast agents and the more widespread use of macrocyclic agents $[66,67]$. In this context, it may be noted that the ongoing GRIP study (Safety of Gadobutrol in Renally Impaired Patients, ClinicalTrials.gov identifier, NCT00828737) has encountered no evidence of NSF in any of the 928 patients investigated to date [68].

More recently, residual gadolinium has been detected in patients with normal renal function. Abnormal T1 shortening in the dentate nucleus and globus pallidus of the brain on unenhanced MRI was first described by Kanda et al., in patients who had previously undergone repeated CE-MRI [69]. It has since been demonstrated that the strength of such T1 shortening correlates to the number of previous GBCA administrations [70, 71], and the dose-dependent accumulation of gadolinium 
in the neuronal epithelium and interstitium $[72$, 73]. Furthermore, akin to NSF, this phenomenon has been linked to previous administration of linear GBCA, but not macrocyclic agents [74, 75]. The clinical consequences of gadolinium crossing the blood-brain barrier and being deposited in neuronal tissues is not yet clear, and further investigation into the biodistribution of gadolinium is warranted [76].

\section{KEY ADVANCES IN CE-MRI INDICATIONS}

The field of CE-MRI has undergone extensive development [77]—examples of major advances are described in the following sections.

\section{Central Nervous System}

Early studies during GBCA development showed that CE-MRI had utility for brain imaging [17] due to the possibility to enhance areas with a disrupted blood-brain barrier corresponding to tumors [78] and many inflammatory/infectious disorders. GBCAs were also shown to enhance tumors with a clear delineation and differentiation from perifocal oedema [79]. Imaging of primary and secondary central nervous system (CNS) tumors is now a major clinical application of routine CE-MRI (Fig. 2) [80], with superior imaging performance and greater versatility compared with other imaging techniques including CT [81]. CE-MRI provides information on the location, classification, and grade of lesions, assisting in directing biopsy, treatment planning and monitoring of the response to therapy [81]. Higher relaxivity agents [82], higher field strengths (e.g., $3 \mathrm{~T}$ or higher) [83] and time-resolved imaging [84] have improved image spatial and temporal resolution and quality, increasing sensitivity for detecting smaller metastatic lesions [85, 86]. Other current applications of CE-MRI in the CNS include the assessment of vascular disease (stroke and vascular malformations), and inflammatory, neurodegenerative and infectious diseases.

Contrast-enhanced magnetic resonance imaging is the gold standard for imaging patients with multiple sclerosis (MS). Applications of MRI in MS were first investigated in the early 1980s, where the technique demonstrated superior ability to detect lesions in the brain and spinal cord compared with CT [87-89]. Enhancing MS lesions on CE-MRI signify new inflammatory activity and a breakdown of the blood-brain barrier, whereas active and inactive lesions may be indistinguishable on unenhanced T2-weighted images. This enhancement pattern is valuable to monitor MS lesion activity and response to treatment [90, 91]. The value of CE-MRI for management of MS was reflected by inclusion of this modality in the McDonald criteria, originally in 2001 [92] and later in the 2005 and 2010 revised guidelines $[93,94]$.

The principle of CNS perfusion imaging was first described in a rat model of cerebral blood volume and cerebral blood flow in 1988 [95]. Ten years later, perfusion imaging was routinely used to demonstrate poorly perfused brain tissue in stroke patients that was not observable on T2-weighted sequences [96]. The kinetic parameters associated with perfusion imaging, such as relative cerebral blood flow (rCBF) and relative cerebral blood volume (rCBV) estimates, have been defined, quantified, and validated against established techniques such as SPECT (single-photon emission CT) [97]. Perfusion sequences are now widely incorporated in MRI protocols to quantify the extent of ischemia and 

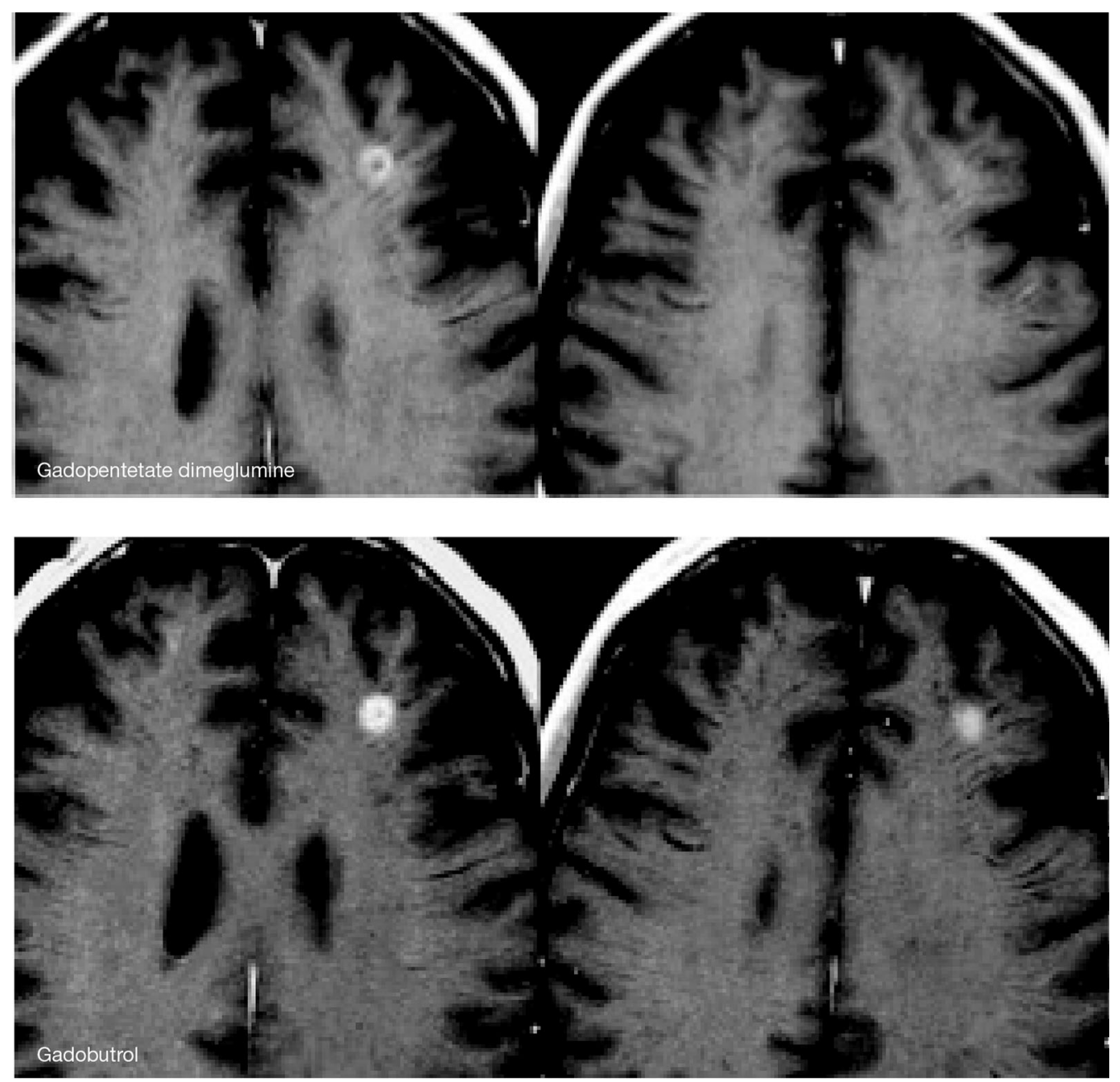

Fig. 2 Contrast-enhanced magnetic resonance imaging images of brain metastases [80]. Reproduced by permission of SAGE publications Ltd., Los Angeles, New Delhi,

hypoperfused tissue, with capability to target and optimize reperfusion therapy [98].

Functional MRI techniques such as perfusion imaging are being utilized for brain tumor imaging, based on the principle of increased tumor vascularity. Determination of a threshold value for rCBV on CE-MRI has shown predictive value for differentiating high- and low-grade cerebral tumors [99] and such a threshold can predict lesion progression and the outcome for patients with such tumors (Fig. 3) [100]. Other perfusion parameters, including mean transit time and time to peak enhancement, have also
Singapore and Washington DC, from Anzalone et al. [80], Copyright (@ Informa Healthcare, 2014)

been investigated as predictive markers in brain tumor imaging, although they are subject to variability and their biological relevance remains unclear. Dynamic contrast-enhanced (DCE) MRI and dynamic susceptibility contrast (DSC) MRI have also found a role in tumor imaging to assess vascular permeability and angiogenesis, respectively. Furthermore, DCE and DSC are commonly applied in acute stroke imaging to assist the differential evaluation of reversibly and irreversibly injured tissue.

Perfusion imaging techniques are advancing rapidly and a recently reported fast, 

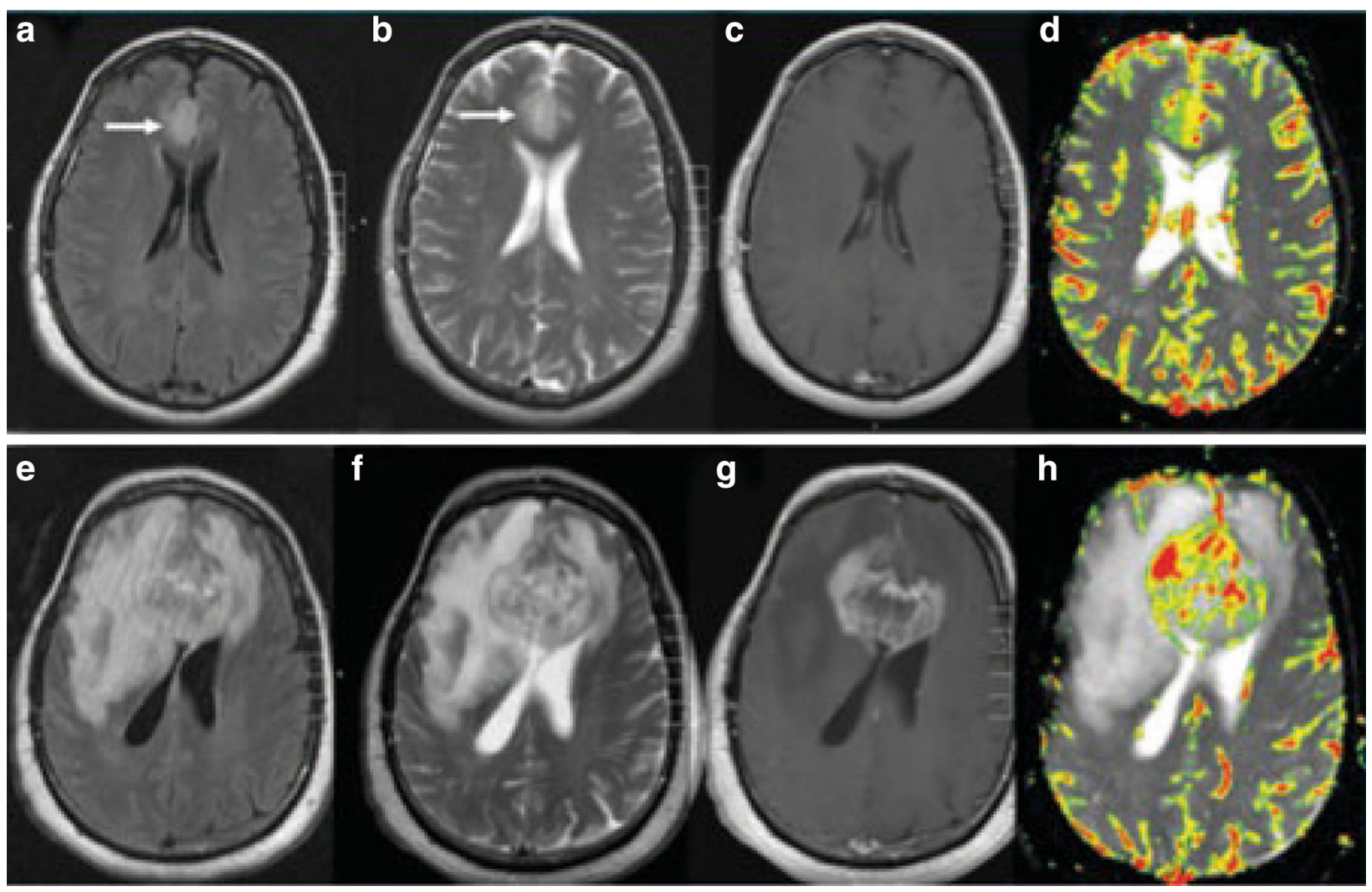

Fig. 3 MR perfusion images for a pathologically proven mixed oligoastrocytoma. Images a-d show baseline examination (a FLAIR; b T2-weighted pre-contrast; c T1-weighted post-gadopentetate dimeglumine; d dynamic susceptibility-weighted perfusion image with relative $\mathrm{CBV}$ color overlay map), which demonstrated a high baseline rCBV of 4.23, indicative of a high-grade

time-resolved sequence with good spatial and temporal resolution has shown promise for the estimation of rCBF and rCBV for MS lesions; this technique is predicted to improve the quantification of haemodynamics in a range of cerebral pathologies [101].

\section{Magnetic Resonance Angiography}

In the early 1990s, the imaging technique of contrast-enhanced MRA was described [102, 103], which ultimately allowed less invasive and more rapid assessment of the anatomy and blood flow of vascular structures than tumor. Images $\mathbf{e}-\mathbf{h}$ show the equivalent sequences at 18-week follow-up, and demonstrate substantial increase in tumor volume and a rCBV of 13.37 [100]. $r C B V$ relative cerebral blood volume, FLAIR fluid-attenuated inversion recovery, $M R$ magnetic resonance. Reproduced from Law et al. [100], Copyright 2014, with permission from The Radiological Society of North America $\left(\right.$ RSNA $\left.^{\circledR}\right)$

intra-arterial digital subtraction angiography (DSA), without the radiation burden of CT-based angiography techniques. Injecting contrast while the patient was inside the scanner and synchronizing the bolus peak arterial phase with acquisition of central k-space data demonstrated preferential arterial enhancement, without excessive venous or background tissue enhancement, providing favorable sensitivity and specificity for the diagnosis of stenoses and occlusions [104, 105]. Although signal-to-noise ratio (SNR) on MR images usually decreases with accelerated imaging, development of a faster, breath-hold 
abdominal MRA technique in 1995 surprisingly provided improvements of $25-50 \%$ and $60-120 \%$ in SNR and contrast-to-noise ratio, respectively, with significantly reduced motion-related image blurring compared to the slower free breathing technique [106]. Introduction of a time-resolved sequence in 1996, using view sharing with oversampling of the center of k-space, provided additional temporal information on blood flow dynamics, while maintaining the excellent delineation of vessels provided by the breath-hold technique, and reducing the flow-related artifacts that were sometimes seen [107]. It was further realized, in 1997, that correct GBCA bolus timing could approximately double SNR in the aorta and portal vein [108], and this subsequently led to the development of a number of semi-automated bolus detection tools for optimization of CE-MRA acquisition. A further advance in MRA came in 1998 with the introduction of moving-bed techniques [109], allowing the GBCA bolus to be tracked over four or five fields of view, providing 'head-to-toe' angiographic images in a single examination.

Today, CE-MRA is widely used for imaging the vascular anatomy in patients with known or suspected peripheral arterial occlusive or aneurysmal disease, as well as various less commonly encountered conditions that affect the non-coronary vasculature [110]. Through advances in technology and the availability of suitable contrast agents, CE-MRA has evolved into a real-time imaging technique that is a highly valuable alternative to CT angiography and intra-arterial DSA [111], with the advantages of avoiding ionizing radiation, iodinated contrast agents, and the need for arterial puncture or manipulation (as required for DSA), making MRA particularly useful in patients requiring repeated imaging. Radial/ spiral acquisitions that oversample the center of k-space, combined with compressed sensing technology and iterative Bayesian reconstruction techniques, promise to accelerate these sparse MRA data acquisitions by several orders of magnitude [112-114].

\section{Cardiac Imaging}

Gadolinium-based contrast agent wash-in and wash-out characteristics were initially described to differentiate infarcted and normal myocardial tissue in a rabbit model in 1996, with marked differences in contrast kinetics between normal tissue, infarct rim and infarct core regions, which correlated with the severity of microvascular damage [115]. Differentiation of areas of damaged myocardium from areas that are structurally intact using CE-MRI at 10-20 min p.i. has been termed 'delayed gadolinium enhancement' or 'late gadolinium enhancement' (LGE) imaging. Various studies have found LGE imaging to be a fast, robust, and highly valuable method to determine myocardial viability in patients with left ventricular dysfunction [116]. Kim et al. and Gerber et al. were the first to report that the likelihood of improvement in regional myocardial contractility following revascularization is negatively correlated with the size of a myocardial infarction, as depicted by the transmural extent of hyperenhancement at pretreatment CE-MRI [117, 118]. LGE has also proved to be an accurate measure to detect myocardial scars, myocardial fibrosis, and myocarditis [119].

Advances in MR hardware and software have also led to the widespread adoption of MR myocardial perfusion imaging (MPI) in patients with suspected coronary artery disease (CAD). In MR-MPI, the initial upslope of dynamic (time-resolved) perfusion CE-MRI signal enhancement under rest and stress (adenosine 
stimulation) accurately depicted significant CAD, compared with invasive coronary angiography as a Ref. [120]. Receiver operating characteristic analyses revealed a clear cut-off value enabling determination of significant CAD, with high sensitivity and specificity (88\% and 90\%, respectively) [120]. A meta-analysis of trials investigating cardiac SPECT, positron emission tomography (PET) and MRI perfusion imaging confirmed the high diagnostic accuracy of MR-MPI for detection of obstructive CAD, with the benefit of avoiding the ionizing radiation associated with the other techniques [121]. The superiority of combined LGE and perfusion cardiac imaging over SPECT for the diagnosis of coronary artery disease has also recently been established in a large, prospective multicenter trial [122]. 3.0 T CE-whole-heart coronary angiography is undergoing preliminary clinical investigations and achieving encouraging results [123, 124]. If this technique proves successful, it may form part of a 'one-stop-shop' examination of CAD, providing information on the anatomy of the heart and the large blood vessels (including the coronary artery), ventricular wall motion, cardiac function, the heart valves, myocardial perfusion, myocardial viability and cardiac metabolism.

Today, cardiac MRI has the capability to visualize cardiac function and morphology, and has become a standard imaging modality in a range of clinical applications including assessment of valvular disease, myocarditis and cardiomyopathies, and congenital heart disease $[125,126]$.

\section{Abdomen}

The first CE-MRI examination of the liver was performed in 1984, as part of a case series investigating the efficacy and safety of gadopentetate dimeglumine-enhanced MRI [22]. Assessment of the dynamic CE-MRI enhancement pattern has become key for the differentiation of benign and malignant lesions in the liver, pancreas and kidneys, as well as elsewhere in the body [127]. Major advances in this field were the introduction of fast breath-hold techniques and effective respiratory triggering, which reduced respiratory- and motion-induced artifacts while improving the sensitivity of imaging [128-130].

Another major advance was the advent of hepato-specific contrast agents. The first liver-specific CE-MRI results were published in 1991, describing manganese dipyridoxal diphosphate enhancement of the liver parenchyma and clearance into the gallbladder (this agent has currently limited worldwide availability) [131]. Gadobenate dimeglumine was then demonstrated to exhibit a small amount of hepatic excretion in humans (3-5\%) [132], meaning that a liver-specific imaging phase could be discerned during delayed imaging (1-2 h p.i.).

The agent gadoxetic acid (primovist/eovist) was developed as a highly liver-specific contrast medium. Gadoxetic acid is excreted almost equally via the liver and kidneys in humans and provides an earlier hepato-specific imaging time (15-20 min p.i.) compared with gadobenate [133]. A seminal manuscript by Weinmann, published in 1991, described the preclinical results for gadoxetic acid, highlighting its protein binding properties, low toxicity and uptake properties in rat hepatocytes, predicting gadoxetic acid to play a future role as a hepatobiliary contrast agent for MRI in clinical practice [134]. The clinical trials in humans that followed established the value of gadoxetic acid for liver MRI, and more specifically for the detection and differentiation of focal liver lesions in the cirrhotic and 

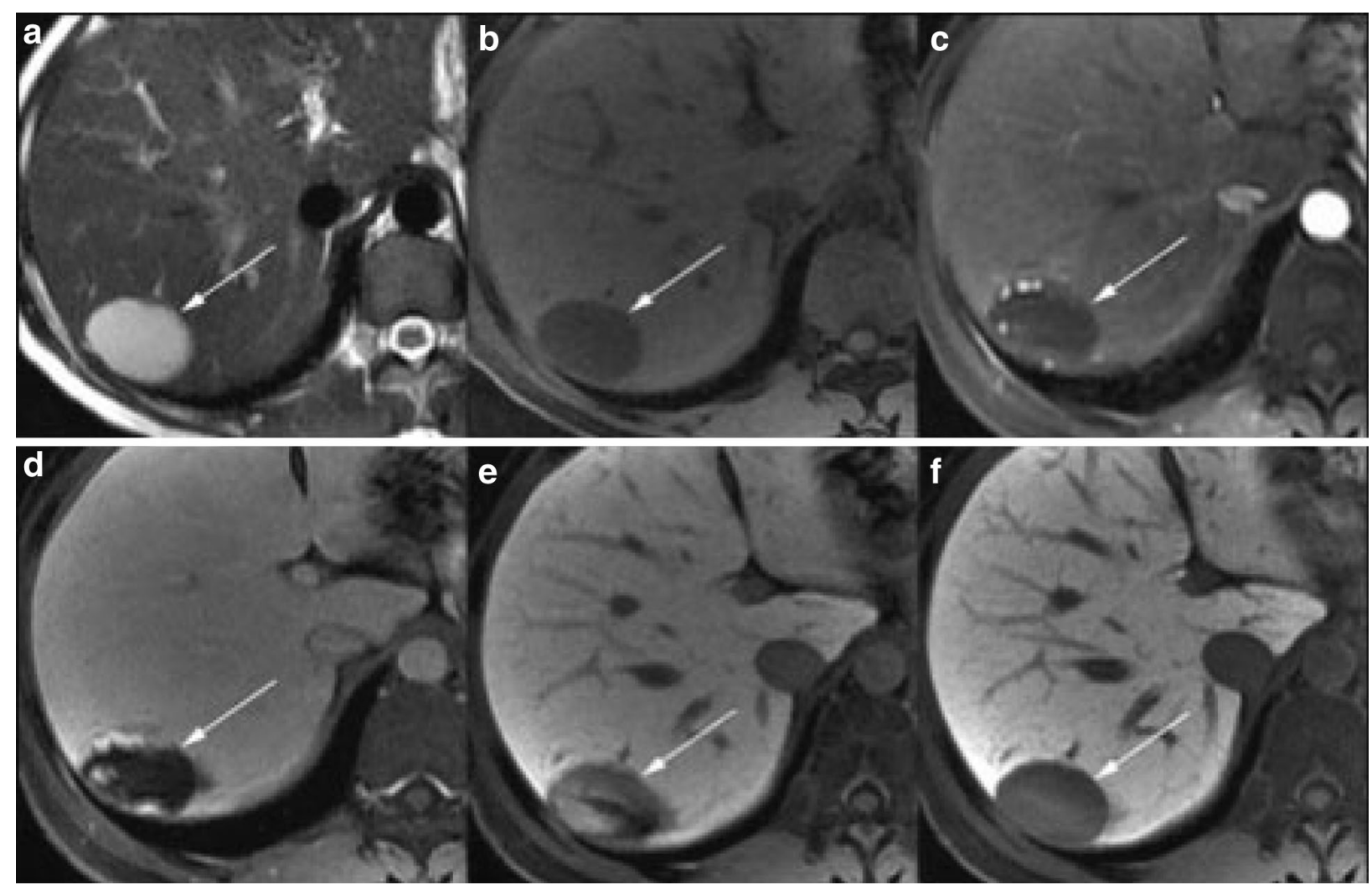

Fig. 4 Magnetic resonance imaging of the liver in a patient with chronic hepatitis $C$. Images $\mathbf{a}$ and $\mathbf{b}$ show pre-contrast T2- and T1-weighted images, respectively; images $\mathbf{c}-\mathbf{f}$ were obtained $20 \mathrm{~s}, 1,5$ and $25 \mathrm{~min}$, respectively, after injection of gadoxetic acid. A lesion in segment VII of the liver demonstrates hyperintensity on pre-contrast T2-weighted image, and hypointensity on T1. Post-contrast, the mass

noncirrhotic liver (Fig. 4) [133, 135, 136]. Reflecting the value of gadoxetic acid-enhanced MRI, this imaging method was included in the 2010 guidelines of the Japan Society of Hepatology for the diagnosis of hepatocellular carcinoma in chronic liver disease [137]. More recently, further applications of gadoxetic acid-enhanced MRI have been investigated, including for cholangiopancreatography and biliary imaging $[138,139]$. The potential utility of gadoxetic acid-enhanced MRI has also been suggested for the assessment of the liver pre- and post-treatment (surgery or locoregional has peripheral puddling of contrast in the arterial phase (c) which progressively coalesce (d, e). In the hepatocyte phase $(\mathbf{f})$, the mass is hypointense to the liver with similar signal intensity to blood vessels. Imaging features are characteristic of haemangioma [135]. Reprinted from Cruite et al. [135], with permission from the American Journal of Roentgenology

therapy), including the quantitative and regional assessment of liver function [140-143].

Contrast-enhanced magnetic resonance imaging has also proven useful, alongside multidetector CT, for accurate and sensitive characterization of renal masses; however, MRI has shown particular value as a problem-solving tool in this field, and advanced techniques, such as perfusion and diffusion imaging, are now being investigated for the assessment of renal lesions and renal function (MR nephrography) [144, 145].

CE-MR enterography for imaging the small bowel provides similar spatial resolution and 
improved contrast resolution compared to CT for investigation of gastrointestinal tumors and inflammatory bowel disease [146], and it shows promise for the future in terms of differentiating active from chronic bowel disease and non-invasive monitoring of response to therapy [147]. The advantage of eliminating ionizing radiation with CE-MRI compared with CT is particularly important in young patients with inflammatory bowel disease who require numerous repeated examinations over many years.

Contrast-enhanced magnetic resonance imaging is becoming a standard modality to image malignancies in the pelvis, with analysis of dynamic contrast kinetics able to aid visualization of tumor vascularization and differentiation of benign from malignant prostate and ovarian tumors [148, 149]. For such tumors, improved diagnostic confidence in assessment of lesion type, extension and response to therapy has been demonstrated for multiparametric MRI techniques combining DCE with other functional parameters, particularly diffusion-weighted imaging (DWI) [150-152].

\section{Breast}

Contrast-enhanced magnetic resonance imaging of breast lesions was reported in a preliminary study in 1986, and was shown to be more accurate than X-ray mammography and unenhanced MRI [153]. In the following years, various technical developments were described [154, 155]. CE-MRI has since been demonstrated to detect more ductal carcinoma in situ than mammography, and in particular more high-grade disease, suggesting that CE-MRI is superior to mammography for diagnosis of the most clinically relevant, potentially invasive tumors [156, 157]. An explanation for the difference in performance between these modalities is that mammography demonstrates microcalcifications due to apoptosis of slowly growing cancers, whereas MRI detects changes in the local microvasculature indicative of aggressively growing cancers [158]. CE-MRI has also been shown to be highly sensitive for the detection of cancer foci in the contralateral breast of women diagnosed with unilateral disease [159]. Furthermore, neither mammography nor ultrasound could improve the cancer yield provided by CE-MRI alone when screening women at risk [160].

DCE enhancement kinetics have shown value for the evaluation of mass-like breast tumors, especially for morphologically equivocal lesions, with characteristic signal time-intensity curves able to differentiate benign from malignant tumors [161]. Following early initial tumor enhancement, a signal intensity decline (type III 'washout' curve) or plateau (type II curve) is characteristic of invasive breast cancer, whereas benign masses tend to exhibit a type 1 curve with 'persistent' signal enhancement (Fig. 5) [161].

Today, CE-MRI is an established tool for determining the morphological and functional characteristics of breast tumors, and is recommended by international societies for screening women with $>20 \%$ lifetime risk of breast cancer, to aid exact local staging of the extent of disease, as a guide for biopsy, and to evaluate treatment response [162, 163].

\section{Musculoskeletal System}

Magnetic resonance imaging has been used to image the musculoskeletal system since the early days of the modality, as MRI demonstrated good soft tissue contrast, spatial 


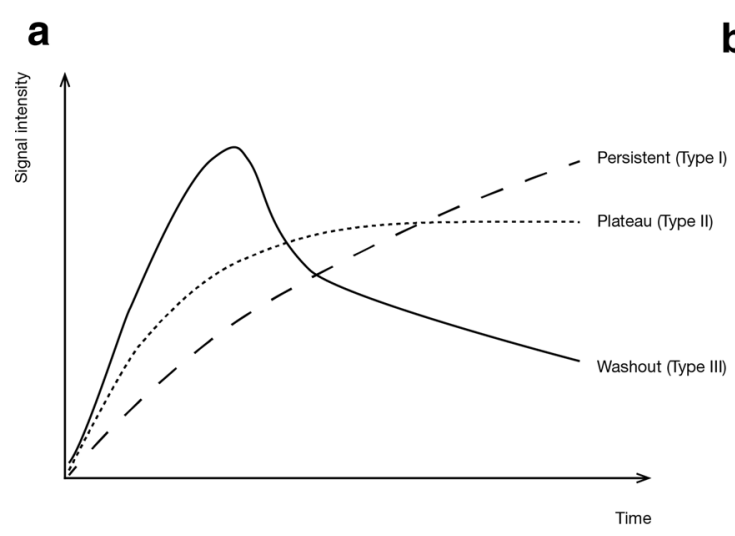

Fig. 5 a Schematic dynamic contrast enhancement curves in CE-MRI of the breast; $\mathbf{b}$ bilateral CE-MRI breast images: dynamic post-contrast injection non-subtracted (top) and subtracted (bottom) images. Mass showed irregular shape, spiculated borders, heterogeneous internal enhancement and fast initial enhancement followed by

resolution and multi-planar capabilities, and sequences could be adapted for optimal contrast between muscle, bone marrow and abnormal tissue [164]. The indications for musculoskeletal MRI fall into three main categories: tumors, infectious diseases and joint damage [165]. CE-MRI is employed to gain additional information in cases of complicated osseous and soft-tissue infection (especially when extent and necrosis are of concern), and for the evaluation of articular injuries and post-operative joint status [165]. For joint assessment, MR arthrography has become a useful alternative to conventional MRI, with GBCA administration performed intravenously (indirect arthrography) or into the target joint (direct arthrography) [166]. Higher magnetic field strength, specialized coils, and improvements in pulse sequences and post-processing have led to increased SNR and soft tissue contrast. Nonetheless, more recent technological advances have furthered the capabilities of musculoskeletal MRI, including kinematic imaging of joint motion, MR spectroscopy and cartilage mapping [167]. early washout (signal intensity/time curve; right), suggestive of a malignant lobular invasive carcinoma [161] CE-MRI contrast-enhanced magnetic resonance imaging. Reproduced from Kuhl [161], Copyright 2014, with permission from The Radiological Society of North America $\left(\mathrm{RSNA}^{\circledR}\right)$

\section{CURRENT TECHNOLOGICAL TRENDS AND CLINICAL CHALLENGES}

Contrast-enhanced magnetic resonance imaging has become accepted as a valuable non-invasive, efficient and safe diagnostic imaging modality that is utilized in radiology departments worldwide. Current trends in the use of existing MR technologies are toward a greater standardization-and simplification-of protocols across centers, with the benefits of uniform performance and interpretation of imaging studies. Continuing research is also extending the applications of current contrast agents, so that individual agents can now be used to image an increasing number of body regions in a single examination.

MRI acquisition times have shortened substantially over the past 25 years by increasing gradient performance and with new acquisition methods utilizing k-space undersampling, parallel imaging and, more recently, compressed sensing. The wider availability of MRI scanners with a $3 \mathrm{~T}$ field 
strength has also brought possibilities for higher image quality and shorter scan times [168].

The growing importance of MRI as a diagnostic tool has been underpinned by its capacity for multiparametric data acquisition, including DWI, DCE, elastography and MR spectroscopy, alongside conventional MRI protocols. Multiparametric imaging has enabled more accurate assessment of normal and disease-associated tissue characteristics in terms of cellularity (diffusion restriction), vascularization (DSC), permeability (DCE), fibrosis and metabolite levels, leading to greater certainty of diagnosis and improved patient outcome. Multiparametric MRI is advancing imaging capabilities in many fields, with a special focus on indications where anatomical imaging alone has in the past been associated with limited accuracy, such as breast and prostate cancer imaging [169]. A recent trend in the development of MRI has been the investigation of integrated multimodality imaging, particularly MR/PET [170]. While PET/CT has been established as a diagnostic tool in cancer imaging for the past decade, MR/ PET offers exciting possibilities for gathering extensive morphologic and hybrid (i.e. both PET and MRI) functional information. More research is required to establish the most appropriate clinical applications of MR/PET, based on diagnostic performance, technical feasibility, practicality and cost in relation to existing techniques [170]. MR/PET techniques will also require changes in data acquisition, data processing, and image processing and interpretation when compared with PET/CT [171].

The fast pace of technological innovation in $\mathrm{MR}$ is in itself a challenge for clinical practitioners. CE-MRI acquisition techniques are continually changing, and the modern radiologist must keep abreast of the latest developments while ensuring that others on the clinical team (nurses, technicians, etc.) are also appropriately educated and trained. As the reported applications of MRI continue to grow in the literature, there is a related need for expert recommendations to provide guidance on the optimal parameters and protocols, interpretation and reporting of the imaging results. For example, as described previously, dynamic CE-MRI perfusion parameters can aid in grading and predicting the progression of brain tumors $[99,100]$ and show promise as markers to monitor response to therapy [172]; however, the variations in practice observed between centers indicate a need for a greater standardization of protocols and the utilization of the latest diagnostic algorithms [100].

The role of CE-MRI in disease screening programs is an ongoing topic of discussion, with both health-economic and clinical repercussions. CE-MRI has demonstrated high sensitivity and specificity for the detection of liver cancer [173] and, as discussed above, CE-MRI of the breast provides a high cancer yield and is recommended for screening women at high risk [160, 162]. Currently, the imaging time and cost of a standard CE-MRI examination limits the use of MRI in screening programs. However, the feasibility of an MRI examination that uses limited sequences but retains sufficient sensitivity for screening is under discussion. This approach could shift the role of MRI in screening, decrease the cost per MRI examination and make MRI screening more cost-effective [174].

\section{FUTURE PERSPECTIVES}

As the field of CE-MRI expands, there are many current research avenues and trends that in the future could prove important to clinical practice. In the following sections, four of 
these potentially interesting areas are discussed; however, we acknowledge that many more exciting avenues exist.

\section{Technological Advances: Higher Acceleration}

Newer signal processing technologies, such as compressed sensing and Bayesian iterative reconstruction methods are allowing the rapid acquisition of undersampled k-space data, permitting entire 3D images to be reconstructed from relatively few measurements. This technique allows acquisition of $3 \mathrm{D}$ data sets with preserved spatial resolution in a fraction of the standard examination time. Preliminary studies are demonstrating the capabilities of this technology, including clear visualization of the cerebral arteries and many branches on whole-head CE-MRA images (generated with an acceleration factor $>100,1 \mathrm{~mm}^{3}$ resolution and a frame rate of approximately one full 3D dataset per second) [175], functional cardiac MRI of the whole heart within one breath hold [176] or using a free breathing technique [177], and high-resolution dynamic liver imaging at four frames per second [178, 179].

This approach is likely to have an impact in many areas, initially for dynamic processes but eventually for all clinical MRI procedures, leading to an improved patient care through shorter and less invasive diagnostic examinations.

\section{Role of Contrast Agents}

Contrast media will be indispensable in most MRI examinations in the foreseeable future. The type of contrast medium selected and the dose that is injected will likely reflect changes in knowledge and techniques. Greater availability of MRI scanners with extended field of view coils and a $3 \mathrm{~T}$ field strength has provided an opportunity to improve the sensitivity of imaging and to allow contrast dose reduction without compromising image quality [180]. Since a dose of contrast agent redistributes throughout the entire body, scanners with large coil arrays can be used to quickly screen extensive areas of anatomy, dramatically increasing the information obtained with a single injection (compared to imaging with scanners limited to a single station field of view). The number of CE-MRI procedures performed globally is likely to grow in the future, as the applications of MRI expand, as this modality becomes available to more patients, and as the information obtained from a single contrast injection increases. Technological advances are likely to facilitate the optimization of MRI protocols, reduce examination time while enriching the value of the MRI examination to the patient.

\section{Higher Relaxivity Contrast Agents}

Despite the major advances in CE-MRI in recent times, there are pathologies that cannot be fully assessed by MRI. In order to increase the sensitivity of CE-MRI in certain pathologies, contrast agents with substantially higher relaxivity will be required.

The efficiency of GBCAs, defined by their T1-relaxivity, is in part dependent on the number of water molecules directly bound to the $\mathrm{Gd}^{3+}$ complex $(q)$, their mean residence time $\left(\tau_{\mathrm{m}}\right)$ and the number and residence times of water molecules in the second hydration sphere (Fig. 6) [181]. GBCAs induce proton relaxation by creating a fluctuating magnetic field, which can arise from tumbling of the molecule in solution (described by the rotational correlation time, $\tau_{\mathrm{R}}$ ) and excitation 


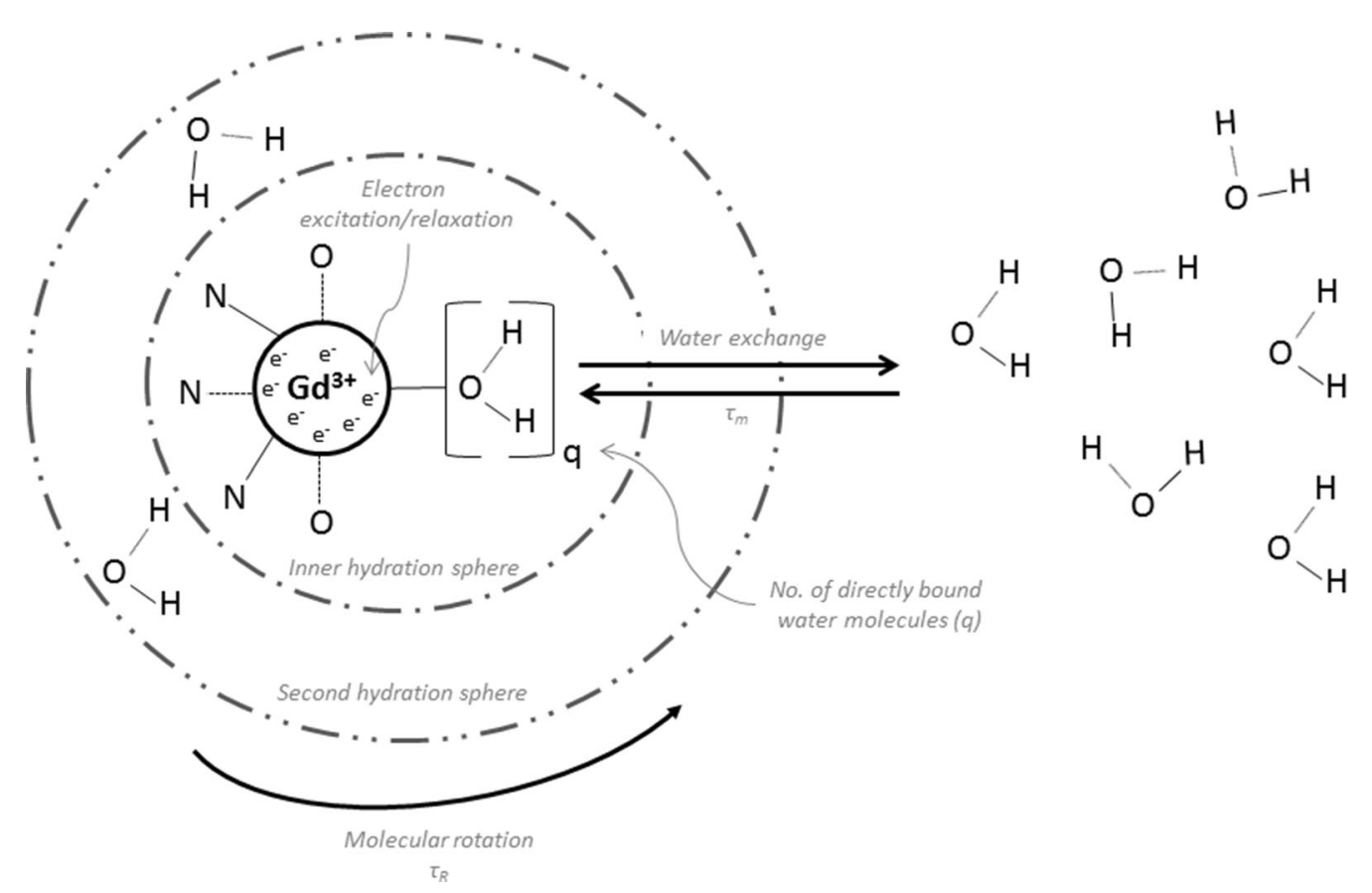

Fig. 6 Schematic diagram of a gadolinium contrast agent molecular complex, and intrinsic factors affecting its T1-relaxivity

and relaxation of electrons in the $\mathrm{Gd}^{3+}$ (Fig. 6) [181]. Molecular size, rigidity of the $\mathrm{Gd}^{3+}$ complex binding to a larger carrier molecule, and physiological protein binding all affect $\tau_{\mathrm{R}}$.

At typical clinical magnetic field strengths (0.5-3 T), the greatest increases of T1-relaxivity for GBCAs have been achieved by slowing the tumbling (increasing $\tau_{\mathrm{R}}$ ) of complexes with $q=1$ and water exchange rates $\left(\tau_{\mathrm{m}}\right)$ of 10-30 ns [182]. Relaxivity can be increased further by increasing $q$ to 2 ; however, this reduces the stability of the complex. Water exchange dynamics and relaxivity can also be adapted by altering groups of atoms within the $\mathrm{Gd}^{3+}$ complex [181, 183]. Tumbling can be slowed (and relaxivity increased) by assembling larger molecules (nanometre scale) with numerous paramagnetic centers, but these molecules are limited in their distribution within the body due to their physical size (molecules $>5$ to $10 \mathrm{~nm}$ cannot freely leave the blood stream) [184, 185]. Examples of this concept are experimental Gd complexes covalently bound to albumin, dextran or macromolecules (dendrimers), which have shown T1-relaxivities 3-5 times greater than clinically available agents [184, 186-188]. For magnetic field strengths of $3 \mathrm{~T}$ and above, the highest relaxivities can be achieved with intermediate $\tau_{\mathrm{R}} \quad(\leq 1 \mathrm{~ns})$ and $\tau_{\mathrm{m}}<2 \mathrm{~ns}$; however, such water residence times would be close to the shortest currently observed (1 ns) [182]. The best strategy for raising relaxivity at high field strength is probably a moderate reversible binding to plasma proteins, a large second sphere of water molecules surrounding the Gd-complex, and an increase in q; however, the benefits of the latter modification should be weighed against any reduction in complex stability. A number of studies using $q=2$ and $q=3$ have investigated this concept [182]. 
Applications of Higher Relaxivity Contrast Agents

\section{Targeted Imaging}

Significant increases in relaxivity will allow substantial reductions in dose for novel agents and will facilitate the development of targeted/ tissue-specific contrast media. Tissue-specific contrast agents are already available, such as gadoxetic acid, which is taken up by a hepatocyte uptake transporter (organic anion-transporting polypeptide 8) in liver parenchyma [189], and the superparamagnetic iron oxide particles (SPIOs), which are sequestered by phagocytic Kupffer cells in the reticuloendothelial system of the liver [190]. Other targeted agent approaches are at an experimental stage: investigations of ultrasmall SPIOs for imaging macrophage activity in lymph nodes and atherosclerotic plaque have been performed, as has labeling of tumors with monoclonal antibodies conjugated to paramagnetic complexes or superparamagnetic nanoparticles [191]. However, the sensitivities of these techniques are not currently adequate for clinical applications, and new agents with significantly increased relaxivity targeted to specific tissues or disease processes will be required. One such experimental agent is EP-2104R, a molecule containing four Gd-complexes that binds with good specificity to fibrin, where it demonstrates a relaxivity per molecule approximately 25 times higher than a conventional GBCA at $1.4 \mathrm{~T}$ [192]. The strong fibrin binding, selectivity and high relaxivity of EP-2104R enabled a clear depiction of occlusive intracranial thrombi in a rat embolic stroke model, where the $\mathrm{Gd}^{3+}$ concentration in the clot was 18-fold higher than in the blood pool [193]. This agent has also demonstrated good visualization of thrombi in a swine model of pulmonary embolism [194], and could depict thrombi in the arterial and venous systems and hearts of patients $[195,196]$.

\section{Monitoring Response to Therapy}

Early information on disease progression and response to therapy has considerable potential benefits for patient management, by promptly highlighting a need to shift therapeutic approaches and by providing cost savings if expensive therapies (e.g., anti-angiogenic agents) are quickly evaluated to be unsuccessful.

A number of quantitative DCE and perfusion parameters are now considered biomarkers with value for the prediction and monitoring of therapeutic response, particularly to date in the oncologic and cardiologic specialties [197-199]. For example, in oncology, perfusion mapping (as a surrogate measure of blood flow) correlates with response to tyrosine-kinase inhibitor therapy in patients with renal tumors [200], and quantitative kinetic parameters of lesion enhancement at DCE can predict whether triple-negative breast cancer patients will respond to neoadjuvant chemotherapy [201]. Animal studies have suggested that quantitative tumor vascularity and perfusion parameters can act as surrogate descriptors for the effect of sorafenib therapy on prostate carcinoma within a week [172] and that, in conjunction with novel contrast agents, the DCE MRI profile is able to indicate early (within $24 \mathrm{~h}$ ) endothelial permeability changes following bevacizumab therapy in a melanoma model [202].

\section{CONCLUSION}

The field of CE-MRI has expanded beyond expectations since the approval of the first MRI contrast agent, gadopentetate dimeglumine, in 1988, and it continues to evolve. Today, CE-MRI is a valuable and 
established modality for multiple indications in many body regions. New techniques are bringing exciting novel possibilities for MRI, alongside associated clinical challenges.

\section{ACKNOWLEDGMENTS}

Sponsorship, article processing charges, and the open access charge for this study were funded by Bayer HealthCare. Writing support was provided by Claire Price of PAREXEL International, and this support was funded by Bayer HealthCare.

All named authors meet the International Committee of Medical Journal Editors (ICMJE) criteria for authorship for this manuscript, take responsibility for the integrity of the work as a whole, and have given final approval for the version to be published.

Disclosures. J Lohrke, T. Frenzel, J. Endrikat and H.Pietsch are employees of Bayer HealthCare.

F. C. Alves, T. M. Grist, M. Law, J. M. Lee, T. Leiner, K. C. Li, K. Nikolaou, M. R. Prince, H. H. Schild. J. C Weinreb and K. Yoshikawa have nothing to disclose.

Compliance with ethics guidelines. This article is based on previously conducted studies and does not involve any new studies of human or animal subjects performed by any of the authors.

Open Access. This article is distributed under the terms of the Creative Commons Attribution-NonCommercial 4.0 International License (http://creativecommons.org/licenses/ by-nc/4.0/), which permits any noncommercial use, distribution, and reproduction in any medium, provided you give appropriate credit to the original author(s) and the source, provide a link to the Creative Commons license, and indicate if changes were made.

\section{REFERENCES}

1. Bloch F. Nuclear induction. Phys Rev. 1946;70(7-8):460-74.

2. Bloembergen N, Purcell EM, Pound RV. Relaxation effects in nuclear magnetic resonance absorption. Phys Rev. 1948;73(7):679-712.

3. Lauterbur PC. Image formation by induced local interactions: examples employing nuclear magnetic resonance. Nature. 1973;242(5394):190-1.

4. Garroway AN, Grannell PK, Mansfield P. Image formation in NMR by a selective irradiative process. J Phys C Solid State Phys. 1974;7(24):L457.

5. Lauterbur PC. All science is interdisciplinaryfrom magnetic moments to molecules to men. In: Frängsmyr T, editor. Les Prix Nobel. The Nobel Prizes 2003. Stockholm: Nobel Foundation; 2004.

6. Mansfield P. Snap-shot MRI. In: Frängsmyr T, editor. Les Prix Nobel. The Nobel Prizes 2003. Stockholm: Nobel Foundation; 2004.

7. Damadian R. Apparatus and method for detecting cancer in tissue. Patent 3,789,832. Feb, 1974.

8. Damadian R, Goldsmith M, Minkoff L. NMR in cancer: XVI. FONAR image of the live human body. Physiol Chem Phys. 1977;9(1):97-100.

9. Lauterbur PC, Dias MHM, Rudin AM. Augmentation of tissue water proton spin-lattice relaxation rates by in vivo addition of paramagnetic ions. In: Dutton $\mathrm{P}$, editor. Electrons to tissues. London: Academic Press; 1978. p. 752-9.

10. Brady TJ, Goldman MR, Pykett IL, et al. Proton nuclear magnetic resonance imaging of regionally ischemic canine hearts: effect of paramagnetic proton signal enhancement. Radiology. 1982;144(2):343-7.

11. Goldman MR, Brady TJ, Pykett IL, et al. Quantification of experimental myocardial infarction using nuclear magnetic resonance 
imaging and paramagnetic ion contrast enhancement in excised canine hearts. Circulation. 1982;66(5):1012-6.

12. Mendonca-Dias MH, Gaggelli E, Lauterbur PC. Paramagnetic contrast agents in nuclear magnetic resonance medical imaging. Semin Nucl Med. 1983;13(4):364-76.

13. Young IR, Clarke GJ, Bailes DR, Pennock JM, Doyle FH, Bydder GM. Enhancement of relaxation rate with paramagnetic contrast agents in NMR imaging. J Comput Tomogr. 1981;5(6):543-7.

14. Runge VM, Stewart RG, Clanton JA, et al. Work in progress: potential oral and intravenous paramagnetic NMR contrast agents. Radiology. 1983;147(3):789-91.

15. Runge VM. Notes on "Characteristics of gadolinium-DTPA complex: a potential NMR contrast agent". AJR Am J Roentgenol. 2008;190(6):1433-4.

16. Gries H, Rosenberg D, Weinmann HJ. Patent application. Patent DE-OS 3129906 A1. 1981.

17. Runge VM, Clanton JA, Price AC, et al. Dyke Award. Evaluation of contrast-enhanced MR imaging in a brain-abscess model. AJNR Am J Neuroradiol. 1985;6(2):139-47.

18. Weinmann HJ, Brasch RC, Press WR, Wesbey GE. Characteristics of gadolinium-DTPA complex: a potential NMR contrast agent. AJR Am J Roentgenol. 1984;142(3):619-24.

19. Bui-Mansfield LT. Top 100 cited AJR articles at the AJR's Centennial. AJR Am J Roentgenol. 2006;186(1):3-6.

20. Laniado M, Weinmann HJ, Schoerner W, Felix R, Speck U. First use of GdDTPA/dimeglumine in man. Physiol Chem Phys Med NMR. 1984;16(2):157-65.

21. Weinmann HJ, Laniado M, Mutzel W. Pharmacokinetics of GdDTPA/dimeglumine after intravenous injection into healthy volunteers. Physiol Chem Phys Med NMR. 1984;16(2):167-72.

22. Carr DH, Brown J, Bydder GM, et al. Gadolinium-DTPA as a contrast agent in MRI: initial clinical experience in 20 patients. AJR Am J Roentgenol. 1984;143(2):215-24.

23. Caravan P, Ellison J, McMurry $T$, Lauffer R. Gadolinium(III) chelates as MRI contrast agents: structure, dynamics, and applications. Chem Rev. 1999;99(9):2293-352.
24. Lin SP, Brown JJ. MR contrast agents: physical and pharmacologic basics. J Magn Reson Imaging. 2007;25(5):884-99.

25. Lauffer RB. Paramagnetic metal complexes as water proton relaxation agents for NMR imaging: theory and design. Chem Rev. 1987;87(5):901-27.

26. Cheng KT, Cheng HY, Leung K. Clinical use of gadobutrol for contrast-enhanced magnetic resonance imaging of neurological diseases. Rep Med Imaging. 2012;2012(5):15-22.

27. Lauffer RB. Magnetic resonance contrast media: principles and progress. Magn Reson Q. 1990;6(2):65-84.

28. Aime S, Caravan P. Biodistribution of gadolinium-based contrast agents, including gadolinium deposition. J Magn Reson Imaging. 2009;30(6):1259-67.

29. Staks T, Schuhmann-Giampieri G, Frenzel T, Weinmann HJ, Lange L, Platzek J. Pharmacokinetics, dose proportionality, and tolerability of gadobutrol after single intravenous injection in healthy volunteers. Invest Radiol. 1994;29(7):709-15.

30. Frenzel T, Lengsfeld P, Schirmer H, Hutter J, Weinmann HJ. Stability of gadolinium-based magnetic resonance imaging contrast agents in human serum at 37 degrees C. Invest Radiol. 2008;43(12):817-28.

31. Tombach B, Bremer C, Reimer $\mathrm{P}$, et al. Pharmacokinetics of $1 \mathrm{M}$ gadobutrol in patients with chronic renal failure. Invest Radiol. 2000;35(1):35-40.

32. Bernardino ME, Young SW, Lee JK, Weinreb JC. Hepatic MR imaging with Mn-DPDP: safety, image quality, and sensitivity. Radiology. 1992;183(1):53-8.

33. Stark DD, Weissleder R, Elizondo G, et al. Superparamagnetic iron oxide: clinical application as a contrast agent for MR imaging of the liver. Radiology. 1988;168(2):297-301.

34. Ferré J-C, Shiroishi MS, Law M. Advanced techniques using contrast media in neuroimaging. Magn Reson Imaging Clin N Am. 2012;20(4):699-713.

35. Restrepo CS, Tavakoli S, Marmol-Velez A. Contrast-enhanced cardiac magnetic resonance imaging. Magn Reson Imaging Clin $\mathrm{N}$ Am. 2012;20(4):739-60. 
36. Serrano LF, Morrell B, Mai A. Contrast media in breast imaging. Magn Reson Imaging Clin N Am. 2012;20(4):777-89.

37. Port M, Idee JM, Medina C, Robic C, Sabatou M, Corot C. Efficiency, thermodynamic and kinetic stability of marketed gadolinium chelates and their possible clinical consequences: a critical review. Biometals. 2008;21(4):469-90.

38. Rohrer M, Bauer H, Mintorovitch J, Requardt M, Weinmann HJ. Comparison of magnetic properties of MRI contrast media solutions at different magnetic field strengths. Invest Radiol. 2005;40(11):715-24.

39. Schmitt-Willich H. Stability of linear and macrocyclic gadolinium based contrast agents. $\mathrm{Br}$ J Radiol. 2007;80(955):581-2.

40. Bremerich J, Bilecen D, Reimer P. MR angiography with blood pool contrast agents. Eur Radiol. 2007;17(12):3017-24.

41. Scott L. Gadobutrol: a review of its use for contrast-enhanced magnetic resonance imaging in adults and children. Clin Drug Investig. 2013;33(4):303-14.

42. Sieber MA. Pharmaceutical and safety aspects of gadolinium-based contrast agents. EJHP Pract. 2009;15(6):24-6.

43. Dona I, Blanca-Lopez N, Torres MJ, et al. Drug hypersensitivity reactions: response patterns, drug involved, and temporal variations in a large series of patients. J Investig Allergol Clin Immunol. 2012;22(5):363-71.

44. Forsting M, Palkowitsch P. Prevalence of acute adverse reactions to gadobutrol-a highly concentrated macrocyclic gadolinium chelate: review of 14,299 patients from observational trials. Eur J Radiol. 2010;74(3):e186-92.

45. Bruder O, Schneider S, Nothnagel D, et al. Acute adverse reactions to gadolinium-based contrast agents in CMR: multicenter experience with 17,767 patients from the EuroCMR Registry. JACC Cardiovasc Imaging. 2011;4(11):1171-6.

46. Geenen RWF, Krestin GP. Non-tissue specific extracellular MR contrast media. In: Thomsen HS, editor. contrast media. Springer: Berlin Heidelberg; 2006. p. 107-14.

47. Gutierrez JE, Koenig S, Breuer J. Overview on the efficacy and safety of gadobutrol: an MRI contrast agent for the CNS, body and vessels. Imaging Med. 2012;4(1):25-40.
48. Knopp MV, Balzer T, Esser M, Kashanian FK, Paul $\mathrm{P}$, Niendorf HP. Assessment of utilization and pharmacovigilance based on spontaneous adverse event reporting of gadopentetate dimeglumine as a magnetic resonance contrast agent after 45 million administrations and 15 years of clinical use. Invest Radiol. 2006;41(6):491-9.

49. Matsumura T, Hayakawa M, Shimada F, et al. Safety of gadopentetate dimeglumine after 120 million administrations over 25 years of clinical use. Magn Reson Med Sci. 2013;12(4):297-304.

50. Prince MR, Palkowitsch P. Safety of gadobutrol in 15,508 patients, data from the interim analysis of the GARDIAN study, a global multicenter prospective non-interventional study. In: The annual meeting of the Radiological Society of North America; November 25-30, 2012 (abstract SSQ08-04).

51. Voth M, Rosenberg M, Breuer J. Safety of gadobutrol, a new generation of contrast agents: experience from clinical trials and postmarketing surveillance. Invest Radiol. 2011;46(11):663-71.

52. Grobner T. Gadolinium-a specific trigger for the development of nephrogenic fibrosing dermopathy and nephrogenic systemic fibrosis? Nephrol Dial Transplant. 2006;21(4):1104-8.

53. Pietsch H, Lengsfeld P, Jost G, Frenzel T, Hutter J, Sieber MA. Long-term retention of gadolinium in the skin of rodents following the administration of gadolinium-based contrast agents. Eur Radiol. 2009;19(6):1417-24.

54. Pietsch H, Lengsfeld $\mathrm{P}$, Steger-Hartmann $\mathrm{T}$, et al. Impact of renal impairment on long-term retention of gadolinium in the rodent skin following the administration of gadolinium-based contrast agents. Invest Radiol. 2009;44(4):226-33.

55. Pietsch $\mathrm{H}$, Pering C, Lengsfeld $\mathrm{P}$, et al. Evaluating the role of zinc in the occurrence of fibrosis of the skin: a preclinical study. J Magn Reson Imaging. 2009;30(2):374-83.

56. Pietsch $\mathrm{H}$, Raschke M, Ellinger-Ziegelbauer $\mathrm{H}$, et al. The role of residual gadolinium in the induction of nephrogenic systemic fibrosis-like skin lesions in rats. Invest Radiol. 2011;46(1):48-56.

57. Sieber MA, Lengsfeld P, Frenzel T, et al. Preclinical investigation to compare different gadolinium-based contrast agents regarding their propensity to release gadolinium in vivo and to trigger nephrogenic systemic fibrosis-like lesions. Eur Radiol. 2008;18(10):2164-73. 
58. Sieber MA, Lengsfeld $\mathrm{P}$, Walter $\mathrm{J}$, et al. Gadolinium-based contrast agents and their potential role in the pathogenesis of nephrogenic systemic fibrosis: the role of excess ligand. J Magn Reson Imaging. 2008;27(5):955-62.

59. Sieber MA, Pietsch H, Walter J, Haider W, Frenzel $\mathrm{T}$, Weinmann HJ. A preclinical study to investigate the development of nephrogenic systemic fibrosis: a possible role for gadolinium-based contrast media. Invest Radiol. 2008;43(1):65-75.

60. Sieber MA, Steger-Hartmann T, Lengsfeld P, Pietsch H. Gadolinium-based contrast agents and NSF: evidence from animal experience. J Magn Reson Imaging. 2009;30(6):1268-76.

61. Steger-Hartmann T, Hofmeister R, Ernst R, Pietsch $\mathrm{H}$, Sieber MA, Walter J. A review of preclinical safety data for magnevist (gadopentetate dimeglumine) in the context of nephrogenic systemic fibrosis. Invest Radiol. 2010;45(9):520-8.

62. Steger-Hartmann T, Raschke M, Riefke B, Pietsch $\mathrm{H}$, Sieber MA, Walter J. The involvement of pro-inflammatory cytokines in nephrogenic systemic fibrosis-a mechanistic hypothesis based on preclinical results from a rat model treated with gadodiamide. Exp Toxicol Pathol. 2009;61(6): 537-52.

63. European Medicines Agency. European Medicines Agency makes recommendations to minimise risk of nephrogenic systemic fibrosis with gadolinium-containing contrast agents. EMEA press office. http://www.ema.europa.eu/ema/ index.jsp?curl=pages/news_and_events/news/2009/ 11/news_detail_000408.jsp\&mid=WC0b01ac058004 d5c1. Accessed Oct 30, 2014.

64. Thomsen $\mathrm{H}$, Morcos $\mathrm{S}$, Almén $\mathrm{T}$, et al. Nephrogenic systemic fibrosis and gadolinium-based contrast media: updated ESUR Contrast Medium Safety Committee guidelines. Eur Radiol. 2013;23(2):307-18.

65. US Food and Drug Administration. FDA Drug Safety Communication: New warnings for using gadolinium-based contrast agents in patients with kidney dysfunction. FDA website. http://www.fda. gov/drugs/drugsafety/ucm223966.htm\#sa. Accessed Oct 30, 2014.

66. Becker S, Walter S, Witzke O, Kreuter A, Kribben A, Mitchell A. Application of gadolinium-based contrast agents and prevalence of nephrogenic systemic fibrosis in a cohort of end-stage renal disease patients on hemodialysis. Nephron Clin Pract. 2012;121(1-2):c91-4.

67. Wang Y, Alkasab TK, Narin O, et al. Incidence of nephrogenic systemic fibrosis after adoption of restrictive gadolinium-based contrast agent guidelines. Radiology. 2011;260(1):105-11.

68. Michaely HJ. Safety of gadobutrol in renally impaired patients: interim results from a prospective international multicenter trial after end of recruitment. In: The 99th scientific assembly and annual meeting of the Radiological Society of North America (abstract 113016599).

69. Kanda T, Ishii K, Kawaguchi H, Kitajima K, Takenaka D. High signal intensity in the dentate nucleus and globus pallidus on unenhanced T1-weighted MR images: relationship with increasing cumulative dose of a gadolinium-based contrast material. Radiology. 2014;270(3):834-41.

70. Errante Y, Cirimele V, Mallio CA, Di Lazzaro V, Zobel BB, Quattrocchi CC. Progressive increase of $\mathrm{T} 1$ signal intensity of the dentate nucleus on unenhanced magnetic resonance images is associated with cumulative doses of intravenously administered gadodiamide in patients with normal renal function, suggesting dechelation. Invest Radiol. 2014;49(10):685-90.

71. Quattrocchi CC, Mallio CA, Errante Y, et al, Gadodiamide and dentate nucleus T1 hyperintensity in patients with meningioma evaluated by multiple follow-up contrast-enhanced magnetic resonance examinations with no systemic interval therapy. Invest Radiol. 2015;50(7):470-2.

72. Kanda $T$, Fukusato $T$, Matsuda $M$, et al. Gadolinium-based contrast agent accumulates in the brain even in subjects without severe renal dysfunction: evaluation of autopsy brain specimens with inductively coupled plasma mass spectroscopy. Radiology. 2015;276(1):228-32.

73. McDonald RJ, McDonald JS, Kallmes DF, et al. Intracranial gadolinium deposition after contrast-enhanced MR imaging. Radiology. 2015;275(3):772-82.

74. Kanda $\mathrm{T}$, Osawa $\mathrm{M}$, Oba $\mathrm{H}$, et al. High signal intensity in dentate nucleus on unenhanced T1-weighted MR Images: association with linear versus macrocyclic gadolinium chelate administration. Radiology. 2015;275(3):803-9.

75. Radbruch A, Weberling LD, Kieslich PJ, et al. Gadolinium retention in the dentate nucleus and globus pallidus is dependent on the class of contrast agent. Radiology. 2015;275(3):783-91.

76. Kanal E, Tweedle MF. Residual or retained gadolinium: practical implications for 
radiologists and our patients. Radiology. 2015;275(3):630-4.

77. Ai T, Morelli JN, Hu X, et al. A historical overview of magnetic resonance imaging, focusing on technological innovations. Invest Radiol. 2012;47(12):725-41.

78. Schoerner W, Kazner E, Laniado M, Sprung C, Felix R. Magnetic resonance tomography (MRT) of intracranial tumours: initial experience with the use of the contrast medium gadolinium-DTPA. Neurosurg Rev. 1984;7(4):303-12.

79. Claussen C, Laniado $M$, Schoerner $W$, et al. Gadolinium-DTPA in MR imaging of glioblastomas and intracranial metastases. AJNR Am J Neuroradiol. 1985;6(5):669-74.

80. Anzalone N, Gerevini S, Scotti R, Vezzulli P, Picozzi P. Detection of cerebral metastases on magnetic resonance imaging: intraindividual comparison of gadobutrol with gadopentetate dimeglumine. Acta Radiol. 2009;50(8):933-40.

81. Essig M, Anzalone N, Combs SE, et al. MR imaging of neoplastic central nervous system lesions: review and recommendations for current practice. AJNR Am J Neuroradiol. 2012;33(5):803-17.

82. Koenig M, Schulte-Altedorneburg G, Piontek $M$, et al. Intra-individual, randomised comparison of the MRI contrast agents gadobutrol versus gadoteridol in patients with primary and secondary brain tumours, evaluated in a blinded read. Eur Radiol. 2013;23(12):3287-95.

83. Krautmacher C, Willinek WA, Tschampa HJ, et al. Brain tumors: full- and half-dose contrast-enhanced MR imaging at $3.0 \mathrm{~T}$ compared with 1.5 T-Initial Experience. Radiology. 2005;237(3):1014-9.

84. Zou Z, Ma L, Cheng L, Cai Y, Meng X. Time-resolved contrast-enhanced MR angiography of intracranial lesions. J Magn Reson Imaging. 2008;27(4):692-9.

85. Anzalone N, Essig $M$, Lee SK, et al. Optimizing contrast-enhanced magnetic resonance imaging characterization of brain metastases: relevance to stereotactic radiosurgery. Neurosurgery. 2013;72(5):691-701.

86. Zhang B, MacFadden D, Damyanovich AZ, et al. Development of a geometrically accurate imaging protocol at 3 Tesla MRI for stereotactic radiosurgery treatment planning. Phys Med Biol. 2010;55(22):6601-15.
87. Kirshner HS, Tsai SI, Runge VM, Price AC. Magnetic resonance imaging and other techniques in the diagnosis of multiple sclerosis. Arch Neurol. 1985;42(9):859-63.

88. Maravilla KR, Weinreb JC, Suss R, Nunnally RL. Magnetic resonance demonstration of multiple sclerosis plaques in the cervical cord. AJR Am J Roentgenol. 1985;144(2):381-5.

89. Young IR, Hall AS, Pallis CA, Legg NJ, Bydder GM, Steiner RE. Nuclear magnetic resonance imaging of the brain in multiple sclerosis. Lancet. 1981;2(8255):1063-6.

90. Barkhof F, Hommes OR, Scheltens P, Valk J. Quantitative MRI changes in gadolinium-DTPA enhancement after high-dose intravenous methylprednisolone in multiple sclerosis. Neurology. 1991;41(8):1219-22.

91. Barkhof F, Rocca M, Francis G, et al. Validation of diagnostic magnetic resonance imaging criteria for multiple sclerosis and response to interferon beta1a. Ann Neurol. 2003;53(6):718-24.

92. McDonald WI, Compston A, Edan G, et al. Recommended diagnostic criteria for multiple sclerosis: guidelines from the International Panel on the diagnosis of multiple sclerosis. Ann Neurol. 2001;50(1):121-7.

93. Polman $\mathrm{CH}$, Reingold SC, Edan G, et al. Diagnostic criteria for multiple sclerosis: 2005 revisions to the "McDonald Criteria". Ann Neurol. 2005;58(6):840-6.

94. Polman $\mathrm{CH}$, Reingold SC, Banwell B, et al. Diagnostic criteria for multiple sclerosis: 2010 revisions to the McDonald criteria. Ann Neurol. 2011;69(2):292-302.

95. Villringer A, Rosen BR, Belliveau JW, et al. Dynamic imaging with lanthanide chelates in normal brain: contrast due to magnetic susceptibility effects. Magn Reson Med. 1988;6(2):164-74.

96. Warach S, Dashe JF, Edelman RR. Clinical outcome in ischemic stroke predicted by early diffusion-weighted and perfusion magnetic resonance imaging: a preliminary analysis. J Cereb Blood Flow Metab. 1996;16(1):53-9.

97. Wirestam R, Ryding E, Lindgren A, Geijer B, Holtas S, Stahlberg F. Absolute cerebral blood flow measured by dynamic susceptibility contrast MRI: a direct comparison with Xe-133 SPECT. Magma. 2000;11(3):96-103.

98. Essig M, Nguyen TB, Shiroishi MS, et al. Perfusion MRI: the five most frequently asked clinical 
questions. AJR Am J Roentgenol. 2013;201(3): W495-510.

99. Law M, Yang S, Wang $\mathrm{H}$, et al. Glioma grading: sensitivity, specificity, and predictive values of perfusion $M R$ imaging and proton $M R$ spectroscopic imaging compared with conventional MR imaging. AJNR Am J Neuroradiol. 2003;24(10):1989-98.

100. Law M, Oh S, Babb JS, et al. Low-grade gliomas: dynamic contrast-enhanced perfusion MR imaging-prediction of patient clinical response. Radiology. 2006;238(2):658-67.

101. Ingrisch $\mathrm{M}$, Sourbron S, Morhard D, et al. Quantification of perfusion and permeability in multiple sclerosis: dynamic contrast-enhanced MRI in 3D at 3T. Invest Radiol. 2012;47(4):252-8.

102. Creasy JL, Price RR, Presbrey T, Goins D, Partain CL, Kessler RM. Gadolinium-enhanced MR angiography. Radiology. 1990;175(1):280-3.

103. Marchal G, Bosmans H, Van HP, Jiang YB, Aerts P, Bauer $H$. Experimental Gd-DTPA polylysine enhanced MR angiography: sequence optimization. J Comput Assist Tomogr. 1991;15(4):711-5.

104. Prince MR, Yucel EK, Kaufman JA, Harrison DC, Geller SC. Dynamic gadolinium-enhanced three-dimensional abdominal MR arteriography. J Magn Reson Imaging. 1993;3(6):877-81.

105. Prince MR. Gadolinium-enhanced MR aortography. Radiology. 1994;191(1):155-64.

106. Prince MR, Narasimham DL, Stanley JC, et al. Breath-hold gadolinium-enhanced MR angiography of the abdominal aorta and its major branches. Radiology. 1995;197(3):785-92.

107. Korosec FR, Frayne R, Grist TM, Mistretta CA. Time-resolved contrast-enhanced 3D MR angiography. Magn Reson Med. 1996;36(3):345-51.

108. Earls JP, Rofsky NM, DeCorato DR, Krinsky GA, Weinreb JC. Hepatic arterial-phase dynamic gadolinium-enhanced MR imaging: optimization with a test examination and a power injector. Radiology. 1997;202(1):268-73.

109. Ho KY, Leiner T, de Haan MW, Kessels AG, Kitslaar PJ, van Engelshoven JM. Peripheral vascular tree stenoses: evaluation with moving-bed infusion-tracking MR angiography. Radiology. 1998;206(3):683-92.

110. Leiner T. Magnetic resonance angiography of abdominal and lower extremity vasculature. Top Magn Reson Imaging. 2005;16(1):21-66.
111. Olin JW, Kaufman JA, Bluemke DA, et al. Atherosclerotic vascular disease conference: writing group IV: imaging. Circulation. 2004;109(21):2626-33.

112. Johnson KM, Lum DP, Turski PA, Block WF, Mistretta CA, Wieben $O$. Improved 3D phase contrast MRI with off-resonance corrected dual echo VIPR. Magn Reson Med. 2008;60(6):1329-36.

113. Mistretta CA. Undersampled radial MR acquisition and highly constrained back projection (HYPR) reconstruction: potential medical imaging applications in the post-Nyquist era. J Magn Reson Imaging. 2009;29(3):501-16.

114. Wu Y, Johnson K, Kecskemeti SR, et al. Time resolved contrast enhanced intracranial MRA using a single dose delivered as sequential injections and highly constrained projection reconstruction (HYPR CE). Magn Reson Med. 2011;65(4):956-63.

115. Kim RJ, Chen EL, Lima JA, Judd RM. Myocardial Gd-DTPA kinetics determine MRI contrast enhancement and reflect the extent and severity of myocardial injury after acute reperfused infarction. Circulation. 1996;94(12):3318-26.

116. Jerosch-Herold M, Kwong RY. Magnetic resonance imaging in the assessment of ventricular remodeling and viability. Curr Heart Fail Rep. 2008;5(1):5-10.

117. Gerber BL, Garot J, Bluemke DA, Wu KC, Lima JAC. Accuracy of contrast-enhanced magnetic resonance imaging in predicting improvement of regional myocardial function in patients after acute myocardial infarction. Circulation. 2002;106(9):1083-9.

118. Kim RJ, Wu E, Rafael A, et al. The use of contrast-enhanced magnetic resonance imaging to identify reversible myocardial dysfunction. N Engl J Med. 2000;343(20):1445-53.

119. Kramer CM. The expanding prognostic role of late gadolinium enhanced cardiac magnetic resonance. J Am Coll Cardiol. 2006;48(10):1986-7.

120. Nagel E, Klein C, Paetsch I, et al. Magnetic resonance perfusion measurements for the noninvasive detection of coronary artery disease. Circulation. 2003;108(4):432-7.

121. Jaarsma C, Leiner T, Bekkers SC, et al. Diagnostic performance of noninvasive myocardial perfusion imaging using single-photon emission computed tomography, cardiac magnetic resonance, and positron emission tomography imaging for the detection of obstructive coronary artery disease: a 
meta-analysis. J Am Coll Cardiol. 2012;59(19): 1719-28.

122. Greenwood JP, Maredia N, Younger JF, et al. Cardiovascular magnetic resonance and single-photon emission computed tomography for diagnosis of coronary heart disease (CE-MARC): a prospective trial. Lancet. 2012;379(9814):453-60.

123. Dabir D, Naehle CP, Clauberg R, Gieseke J, Schild $\mathrm{H}$, Thomas D. High-resolution motion compensated MRA in patients with congenital heart disease using extracellular contrast agent at 3 Tesla. J Cardiovasc Magn Reson. 2012;14(1):75.

124. Yang Q, Li K, Liu X, et al. 3.0 T whole-heart coronary magnetic resonance angiography performed with 32-channel cardiac coils: a single-center experience. Circ Cardiovasc Imaging. 2012;5(5):573-9.

125. Coelho-Filho OR, Rickers C, Kwong RY, Jerosch-Herold M. MR myocardial perfusion imaging. Radiology. 2013;266(3):701-15.

126. Pilz G, Heer T, Harrer E, Ali E, Hoefling B. Clinical applications of cardiac magnetic resonance imaging. Minerva Cardioangiol. 2009;57(3):299-313.

127. Knopp MV, Giesel FL, Marcos H, von Tengg-Kobligk $\mathrm{H}$, Choyke P. Dynamic contrast-enhanced magnetic resonance imaging in oncology. Top Magn Reson Imaging. 2001;12(4):301-8.

128. Low RN, Francis IR, Herfkens RJ, et al. Fast multiplanar spoiled gradient-recalled imaging of the liver: pulse sequence optimization and comparison with spin-echo MR imaging. AJR Am J Roentgenol. 1993;160(3):501-9.

129. Low RN, Alzate GD, Shimakawa A. Motion suppression in MR imaging of the liver: comparison of respiratory-triggered and nontriggered fast spin-echo sequences. AJR Am J Roentgenol. 1997;168(1):225-31.

130. Tanimoto A, Yuasa Y, Jinzaki M, et al. Routine MR imaging protocol with breath-hold fast scans: diagnostic efficacy for focal liver lesions. Radiat Med. 2002;20(4):169-79.

131. Lim KO, Stark DD, Leese PT, Pfefferbaum A, Rocklage SM, Quay SC. Hepatobiliary MR imaging: first human experience with MnDPDP. Radiology. 1991;178(1):79-82.

132. Spinazzi A, Lorusso V, Pirovano G, Taroni $P$, Kirchin M, Davies A. MultiHance clinical pharmacology: biodistribution and MR enhancement of the liver. Acad Radiol. 1998;5(suppl 1):S86-9.

133. Ringe KI, Husarik DB, Sirlin CB, Merkle EM. Gadoxetate disodium-enhanced MRI of the liver: part 1, protocol optimization and lesion appearance in the noncirrhotic liver. AJR Am J Roentgenol. 2010;195(1):13-28.

134. Weinmann HJ, Schuhmann-Giampieri G, Schmitt-Willich H, Vogler H, Frenzel T, Gries H. A new lipophilic gadolinium chelate as a tissue-specific contrast medium for MRI. Magn Reson Med. 1991;22(2):233-7.

135. Cruite I, Schroeder M, Merkle EM, Sirlin CB. Gadoxetate disodium-enhanced MRI of the liver: part 2, protocol optimization and lesion appearance in the cirrhotic liver. AJR Am J Roentgenol. 2010;195(1):29-41.

136. Huppertz A, Balzer $\mathrm{T}$, Blakeborough A, et al. Improved detection of focal liver lesions at MR imaging: multicenter comparison of gadoxetic acid-enhanced MR images with intraoperative findings. Radiology. 2004;230(1):266-75.

137. Kudo M, Izumi N, Kokudo N, et al. Management of hepatocellular carcinoma in Japan: consensus-based clinical practice guidelines proposed by the Japan Society of Hepatology (JSH) 2010 updated version. Dig Dis. 2011;29(3):339-64.

138. Kim KA, Kim MJ, Park MS, et al. Optimal T2-weighted MR cholangiopancreatographic images can be obtained after administration of gadoxetic acid. Radiology. 2010;256(2):475-84.

139. Lee MS, Lee JY, Kim SH, et al. Gadoxetic acid disodium-enhanced magnetic resonance imaging for biliary and vascular evaluations in preoperative living liver donors: comparison with gadobenate dimeglumine-enhanced MRI. J Magn Reson Imaging. 2011;33(1):149-59.

140. Ryeom HK, Kim SH, Kim JY, et al. Quantitative evaluation of liver function with MRI Using Gd-EOB-DTPA. Korean J Radiol. 2004;5(4):231-9.

141. Seidensticker M, Seidensticker R, Mohnike K, et al. Quantitative in vivo assessment of radiation injury of the liver using Gd-EOB-DTPA enhanced MRI: tolerance dose of small liver volumes. Radiat Oncol. 2011;6:40.

142. Van Beers BE, Pastor CM, Hussain HK. Primovist, eovist: what to expect? J Hepatol. 2012;57(2):421-9.

143. Wibmer A, Aliya Q, Steininger R, et al. Liver transplantation: impaired biliary excretion of 
gadoxate is associated with an inferior 1-year retransplantation-free survival. Invest Radiol. 2012;47(6):353-8.

144. Kang SK, Chandarana H. Contemporary imaging of the renal mass. Urol Clin $\mathrm{N}$ Am. 2012;39(2):161-70.

145. Pazahr S, Boss A, Rossi C. Clinical functional MRI of the kidneys. Curr Radiol Rep. 2013;1(2):115-25.

146. Semelka RC, Shoenut JP, Silverman R, Kroeker MA, Yaffe CS, Micflikier AB. Bowel disease: prospective comparison of CT and 1.5-T pre- and postcontrast MR imaging with T1-weighted fat-suppressed and breath-hold FLASH sequences. J Magn Reson Imaging. 1991;1(6):625-32.

147. Grand DJ, Beland M, Harris A. Magnetic resonance enterography. Radiol Clin N Am. 2013;51(1):99-112.

148. Buckley DL, Roberts C, Parker GJM, Logue JP, Hutchinson CE. Prostate cancer: evaluation of vascular characteristics with dynamic contrast-enhanced T1-weighted MR imaginginitial experience. Radiology. 2004;233(3):709-15.

149. Carter JS, Koopmeiners JS, Kuehn-Hajder JE, et al. Quantitative multiparametric MRI of ovarian cancer. J Magn Reson Imaging. 2013;38(6):1501-9.

150. Borren A, Groenendaal G, Moman MR, et al. Accurate prostate tumour detection with multiparametric magnetic resonance imaging: Dependence on histological properties. Acta Oncol. 2014;53(1):88-95 (Epub ahead of print 2013 Sep 16).

151. Levy A, Medjhoul A, Caramella C, et al. Interest of diffusion-weighted echo-planar MR imaging and apparent diffusion coefficient mapping in gynecological malignancies: a review. J Magn Reson Imaging. 2011;33(5):1020-7.

152. Sala E, Kataoka MY, Priest AN, et al. Advanced ovarian cancer: multiparametric MR imaging demonstrates response- and metastasis-specific effects. Radiology. 2012;263(1):149-59.

153. Heywang SH, Hahn D, Schmidt $H$, et al. MR imaging of the breast using gadolinium-DTPA. J Comput Assist Tomogr. 1986;10(2):199-204.

154. Kaiser WA, Zeitler E. MR imaging of the breast: fast imaging sequences with and without Gd-DTPA. Preliminary observations. Radiology. 1989;170(3 Pt 1):681-6.

155. Pierce WB, Harms SE, Flamig DP, Griffey RH, Evans WP, Hagans JE. Three-dimensional gadolinium-enhanced MR imaging of the breast: pulse sequence with fat suppression and magnetization transfer contrast. Work in progress. Radiology. 1991;181(3):757-63.

156. Kuhl CK, Schrading S, Bieling HB, et al. MRI for diagnosis of pure ductal carcinoma in situ: a prospective observational study. Lancet. 2007;370(9586):485-92.

157. Kuhl CK, Schmutzler RK, Leutner CC, et al. Breast MR imaging screening in 192 women proved or suspected to be carriers of a breast cancer susceptibility gene: preliminary results. Radiology. 2000;215(1):267-79.

158. Kuhl CK. Evolution of breast imaging: beyond mammography. Breast. 2011;20(suppl 1):S8.

159. Lehman CD, Gatsonis C, Kuhl CK, et al. MRI evaluation of the contralateral breast in women with recently diagnosed breast cancer. N Engl J Med. 2007;356(13):1295-303.

160. Kuhl C, Weigel S, Schrading S, et al. Prospective multicenter cohort study to refine management recommendations for women at elevated familial risk of breast cancer: the EVA trial. J Clin Oncol. 2010;28(9):1450-7.

161. Kuhl C. The current status of breast MR imaging. Part I. Choice of technique, image interpretation, diagnostic accuracy, and transfer to clinical practice. Radiology. 2007;244(2):356-78.

162. American College of Radiology. ACR practice guideline for the performance of contrast-enhanced magnetic resonance imaging (MRI) of the breast (Resolution 12). American College of Radiology website. http://www.acr.org/ /media/ACR/Documents/PGTS/guidelines/MRI_ Breast.pdf. Accessed Aug 27, 2013.

163. Sardanelli F, Boetes C, Borisch B, et al. Magnetic resonance imaging of the breast: recommendations from the EUSOMA working group. Eur J Cancer. 2010;46(8):1296-316.

164. Scott JA, Rosenthal DI, Brady TJ. The evaluation of musculoskeletal disease with magnetic resonance imaging. Radiol Clin N Am. 1984;22(4):917-24.

165. Cheng SG. Musculoskeletal MRI: contrast and non-contrast applications. Appl Radiol. 2002;31(6):81-6.

166. Steinbach LS, Palmer WE, Schweitzer ME. Special focus session. MR arthrography. Radiographics. 2002;22(5):1223-46.

167. Shapiro L, Harish M, Hargreaves B, Staroswiecki E, Gold G. Advances in musculoskeletal MRI: 
technical considerations. J Magn Reson Imaging. 2012;36(4):775-87.

168. Tanenbaum LN. 3T MRI in clinical practice. Appl Radiol. 2005;34(1):8-17.

169. Selnaes KM, Heerschap A, Jensen LR, et al. Peripheral zone prostate cancer localization by multiparametric magnetic resonance at $3 \mathrm{~T}$ : unbiased cancer identification by matching to histopathology. Invest Radiol. 2012;47(11):624-33.

170. Torigian DA, Zaidi H, Kwee TC, et al. PET/MR imaging: technical aspects and potential clinical applications. Radiology. 2013;267(1):26-44.

171. Gaertner FC, Furst S, Schwaiger M. PET/MR: a paradigm shift. Cancer Imaging. 2013;13:36-52.

172. Cyran CC, Paprottka PM, Schwarz B, et al. Perfusion MRI for monitoring the effect of sorafenib on experimental prostate carcinoma: a validation study. AJR Am J Roentgenol. 2012;198(2):384-91.

173. Liu X, Zou L, Liu F, Zhou Y, Song B. Gadoxetic acid disodium-enhanced magnetic resonance imaging for the detection of hepatocellular carcinoma: a meta-analysis. PLoS One. 2013;8(8):e70896.

174. Pataky R, Armstrong L, Chia S, et al. Cost-effectiveness of MRI for breast cancer screening in BRCA1/2 mutation carriers. BMC Cancer. 2013;13(1):339-47.

175. Lee GR, Seiberlich N, Sunshine JL, Carroll TJ, Griswold MA. Rapid time-resolved magnetic resonance angiography via a multiecho radial trajectory and GraDeS reconstruction. Magn Reson Med. 2013;69(2):346-59.

176. Wech T, Pickl W, Tran-Gia J, et al. Whole-heart cine MRI in a single breath-hold-a compressed sensing accelerated 3D acquisition technique for assessment of cardiac function. Rofo. 2014;186(1):37-41.

177. Zhang S, Uecker M, Voit D, Merboldt KD, Frahm J. Real-time cardiovascular magnetic resonance at high temporal resolution: radial FLASH with nonlinear inverse reconstruction. J Cardiovasc Magn Reson. 2010;12(39):1-7.

178. Agrawal MD, Spincemaille P, Mennitt KW, et al. Improved hepatic arterial phase MRI with 3-second temporal resolution. J Magn Reson Imaging. 2013;37(5):1129-36.

179. $\mathrm{Xu} \mathrm{B}$, Spincemaille $\mathrm{P}, \mathrm{Chen} \mathrm{G}$, et al. Fast $3 \mathrm{D}$ contrast enhanced MRI of the liver using temporal resolution acceleration with constrained evolution reconstruction. Magn Reson Med. 2013;69(2):370-81.

180. Hartung MP, Grist TM, Francois CJ. Magnetic resonance angiography: current status and future directions. J Cardiovasc Magn Reson. 2011;13:19.

181. Dumas S, Jacques V, Sun WC, et al. High relaxivity magnetic resonance imaging contrast agents part 1: impact of single donor atom substitution on relaxivity of serum albumin-bound gadolinium complexes. Invest Radiol. 2010;45(10):600-12.

182. Helm L. Optimization of gadolinium-based MRI contrast agents for high magnetic-field applications. Future Med Chem. 2010;2(3):385-96.

183. Jacques V, Dumas S, Sun WC, Troughton JS, Greenfield MT, Caravan P. High-relaxivity magnetic resonance imaging contrast agents. Part 2. Optimization of inner- and second-sphere relaxivity. Invest Radiol. 2010;45(10):613-24.

184. Barrett T, Kobayashi H, Brechbiel M, Choyke PL. Macromolecular MRI contrast agents for imaging tumor angiogenesis. Eur J Radiol. 2006;60(3):353-66.

185. Huang $\mathrm{CH}$, Tsourkas A. Gd-based macromolecules and nanoparticles as magnetic resonance contrast agents for molecular imaging. Curr Top Med Chem. 2013;13(4):411-21.

186. Misselwitz B, Schmitt-Willich H, Ebert W, Frenzel $\mathrm{T}$, Weinmann HJ. Pharmacokinetics of Gadomer-17, a new dendritic magnetic resonance contrast agent. Magma. $2001 ; 12(2-3): 128-34$.

187. Ogan MD, Schmiedl U, Moseley ME, Grodd W, Paajanen H, Brasch RC. Albumin labeled with Gd-DTPA. An intravascular contrast-enhancing agent for magnetic resonance blood pool imaging: preparation and characterization. Invest Radiol. 1987;22(8):665-71.

188. Wang SC, Wikstrom MG, White DL, et al. Evaluation of Gd-DTPA-labeled dextran as an intravascular MR contrast agent: imaging characteristics in normal rat tissues. Radiology. 1990;175(2):483-8.

189. Kitao A, Matsui O, Yoneda $\mathrm{N}$, et al. The uptake transporter OATP8 expression decreases during multistep hepatocarcinogenesis: correlation with gadoxetic acid enhanced MR imaging. Eur Radiol. 2011;21(10):2056-66.

190. Wang YX. Superparamagnetic iron oxide based MRI contrast agents: current status of clinical 
application. Quant Imaging Med Surg. 2011;1(1): 35-40.

191. Weinmann HJ, Ebert W, Misselwitz B, Schmitt-Willich H. Tissue-specific MR contrast agents. Eur J Radiol. 2003;46(1):33-44.

192. Overoye-Chan K, Koerner S, Looby RJ, et al. EP-2104R: a fibrin-specific gadolinium-based MRI contrast agent for detection of thrombus. J Am Chem Soc. 2008;130(18):6025-39.

193. Uppal R, Ay I, Dai G, Kim YR, Sorensen AG, Caravan P. Molecular MRI of intracranial thrombus in a rat ischemic stroke model. Stroke. 2010;41(6):1271-7.

194. Spuentrup E, Katoh M, Buecker A, et al. Molecular MR imaging of human thrombi in a swine model of pulmonary embolism using a fibrin-specific contrast agent. Invest Radiol. 2007;42(8):586-95.

195. Spuentrup E, Botnar RM, Wiethoff AJ, et al. MR imaging of thrombi using EP-2104R, a fibrin-specific contrast agent: initial results in patients. Eur Radiol. 2008;18(9):1995-2005.

196. Vymazal J, Spuentrup E, Cardenas-Molina G, et al. Thrombus imaging with fibrin-specific gadolinium-based MR contrast agent EP-2104R: results of a phase II clinical study of feasibility. Invest Radiol. 2009;44(11):697-704.

197. Bolan PJ. Magnetic resonance spectroscopy of the breast: current status. Magn Reson Imaging Clin N Am. 2013;21(3):625-39.
198. Calcagno C, Ramachandran S, Millon A, Robson PM, Mani V, Fayad Z. Gadolinium-based contrast agents for vessel wall magnetic resonance imaging (MRI) of atherosclerosis. Curr Cardiovasc Imaging Rep. 2013;6(1):11-24.

199. Sahani DV, Jiang T, Hayano K, et al. Magnetic resonance imaging biomarkers in hepatocellular carcinoma: association with response and circulating biomarkers after sunitinib therapy. J Hematol Oncol. 2013;6:51.

200. Notohamiprodjo M, Sourbron S, Staehler M, et al. Measuring perfusion and permeability in renal cell carcinoma with dynamic contrast-enhanced MRI: a pilot study. J Magn Reson Imaging. 2010;31(2):490-501.

201. Golden DI, Lipson JA, Telli ML, Ford JM, Rubin DL. Dynamic contrast-enhanced MRI-based biomarkers of therapeutic response in triple-negative breast cancer. J Am Inform Assoc. 2013;20(6):1059-66 (Epub ahead of print 2013 Jun 19).

202. Cyran CC, Fu Y, Rogut V, et al. Evaluation of a novel macromolecular cascade-polymer contrast medium for dynamic contrast-enhanced MRI monitoring of antiangiogenic bevacizumab therapy in a human melanoma model. Acta Radiol. 2013;20(10): 1256-63. 